\title{
Review on the recent progress in the preparation and stability of graphene-based nanofluids
}

\author{
Thong Le $\mathrm{Ba}^{1}{ }^{1} \cdot$ Omid Mahian $^{2} \cdot$ Somchai Wongwises $^{3,4} \cdot$ Imre Miklós Szilágyi $^{1}$
}

Received: 25 September 2019 / Accepted: 20 January 2020 / Published online: 31 January 2020

(c) The Author(s) 2020

\begin{abstract}
Graphene has attracted much attention from the science world because of its mechanical, thermal, and physical properties. Graphene nanofluid is well known for its easy synthesis, longer suspension stability, higher heat conductivity, lower erosion, corrosion, larger surface area/volume ratio, and lower demand for pumping power. This article is an audit of experimental outcome about the preparation and stability of graphene-based nanofluids. Numerous researches to prepare and stabilize graphene-based nanofluids have been developed, and it is indispensable to create a complete list of the approaches. This research work outlines the advancement on preparation and assessment methods and the techniques to enhance the stability of graphene nanofluids and outlook prospects.
\end{abstract}

Keywords Graphene $\cdot$ Nanofluids $\cdot$ Synthesis $\cdot$ Stability

$\begin{array}{ll}\text { Abbreviations } \\ \text { AFM } & \text { Atomic force microscopy } \\ \text { BF } & \text { Base fluid } \\ \text { CVD } & \text { Chemical vapor deposition } \\ \text { DI } & \text { Deionized water } \\ \text { DLS } & \text { Dynamic light scattering } \\ \text { DW } & \text { Distilled water } \\ \text { EC } & \text { Electrical conductivity } \\ \text { EG } & \text { Ethylene glycol } \\ \text { GIC } & \text { Graphite intercalation compound } \\ \text { GIO } & \text { Graphite oxide } \\ \text { GNF } & \text { Graphene-based nanofluid } \\ \text { GNP } & \text { Graphene nanoplatelet } \\ \text { GNS } & \text { Graphene nanosheet } \\ \text { GO } & \text { Graphene oxide }\end{array}$

Thong Le Ba

kenty9x@gmail.com

1 Department of Inorganic and Analytical Chemistry, Budapest University of Technology and Economics, Muegyetem rakpart 3, Budapest 1111, Hungary

2 School of Chemical Engineering and Technology, Xi' an Jiaotong University, Xi' an 710049, Shaanxi, China

3 Department of Mechanical Engineering, Faculty of Engineering, King Mongkut's University of Technology Thonburi, Bangmod, Bangkok 10140, Thailand

4 National Science and Technology Development Agency (NSTDA), Pathum Thani 12120, Thailand

$\begin{array}{ll}\text { GON } & \text { Graphene oxide nanosheet } \\ \text { GONF } & \text { Graphene oxide nanofluid } \\ \text { HM } & \text { Hummers method } \\ \text { MHM } & \text { Modified Hummers method } \\ \text { MWCNT } & \text { Multiwalled carbon nanotube } \\ \text { NDG } & \text { Nitrogen-doped graphene } \\ \text { PSD } & \text { Particle size distributions } \\ \text { rGO } & \text { Reduced graphene oxide } \\ \text { SBM } & \text { Supplied by manufacturer } \\ \text { SEM } & \text { Scanning electron microscopy } \\ \text { SHM } & \text { Simplified Hummers method } \\ \text { SPC } & \text { Sedimentation photograph capturing } \\ \text { SWCNT } & \text { Single-wall carbon nanotube } \\ \text { TC } & \text { Thermal conductivity } \\ \text { TEM } & \text { Transmission electron microscopy } \\ \text { ZPT } & \text { Zeta potential test }\end{array}$

\section{Introduction}

Nanofluids, coined by Choi and Eastman [1], are colloidal suspensions of ultrafine metallic or nonmetallic particles in a base matrix host fluid. Some essential requirements should be met, for example, steady-state suspension, low agglomeration of nanoparticles, and the BF should be chemically unchanged. Nanofluids can be divided into two types: metallic nanofluids (metals: $\mathrm{Au}, \mathrm{Ag}, \mathrm{Cu}, \mathrm{Al}, \mathrm{Fe}$; metal oxides: $\mathrm{Al}_{2} \mathrm{O}_{3}, \mathrm{CuO}, \mathrm{Fe}_{3} \mathrm{O}_{4}, \mathrm{SiO}_{2}, \mathrm{TiO}_{2}, \mathrm{ZnO}$, etc.) and nonmetallic 
nanofluids (carbides: $\mathrm{SiC}, \mathrm{TiC}$, carbon materials: graphite, diamond, SWCNT/MWCNT, graphene, etc.) [2]. There are two primary methods to produce nanofluids: the one-step method by creating the BF and nanoparticles together and the two-step method by creating them separately and then mixing [3, 4]. Nanofluids have some important characteristics for different utilizations, for example, high heat conductivity, ultrafast heat transfer ability, good stability, reduction of erosion and friction coefficient, and good lubrication.

Graphene is a form of carbon comprising of a single layer of $s p^{2}$-bonded carbon atoms densely arranged in a honeycomb (hexagonal) lattice. Graphene attracted much attention because it has many unique electrical characteristics like very high carrier mobility. The GNF is well known for its easy synthesis, longer suspension stability, higher TC, lower erosion, corrosion, larger surface area/volume ratio, and lower demand for pumping power [5]. Thus, by using GNFs, the inventory of heat transfer fluid can be reduced, and energy can be saved significantly.

Unlike graphene, the exact structure of GO is still difficult to determine due to its complicated nonstoichiometric nature. For GO the aromatic lattice of graphene is interrupted by epoxide, ketone, carboxylic, and alcohol groups. The GO nanoparticles also have some special characteristics such as special high surface, high convective heat transfer, hydrophilicity, insolubility, and low density [6]. GO is a great interest of researchers due to easy access, low cost, and extensive capability to convert to rGO.

The groups containing the polar oxygen atoms not only bring positive effects in terms of a facilitated aqueous nanofluid but also a disadvantage with a very substantial decrease in sheet conductivity. Therefore, the effective removal of these oxygen species for the preparation of rGO is very important for any applications related to linear and nonlinear conductive nanoparticles [7].
The two primary requirements of an experimental study on nanofluids are synthesis and stability of nanofluids. These greatly affect the utilization of nanofluids in actual applications. This is the reason why these characteristics should be reviewed in the research papers.

In recent years, research on nanofluids has increased dramatically. In 2017, the number of articles covering nanofluids was nearly 2500 , while nanofluids and graphene were 83. Figures 1 and 2 show an exponential growth of publications in nanofluid and GNF research. Graphene and graphene derivative-based nanofluids are becoming essential in the engineering globe [8]. The great prospects are expressed about their utilizations in different fields (Fig. 3) [9].

\section{Preparation of graphene, GO, and rGO}

\section{Preparation of graphene}

The most vital properties of graphene are the strong, light, and good heat conductive material [11]. The heat conductivity value of graphene was $3000-5000 \mathrm{~W} \mathrm{~m}^{-1} \mathrm{~K}^{-1}$ at room temperature [12]. By using AFM, they investigated the intrinsic mechanical properties of monolayers of graphene, in which graphene has a tensile strength of $42 \mathrm{~N} \mathrm{~m}^{-1}$ and a Young's module of $1 \mathrm{TPa}$ [13]. Thus, it can usually be utilized for improving the quality of other materials. It is a great material to produce heat-spreading solutions like heat sinks. Graphene is useful in microelectronics [14] and larger applications [15]. Graphene is additionally a very hopeful material to be utilized in batteries and supercapacitors with higher energy storage and faster charge [16-18]. Graphene is extremely sensitive to the environment, so this extends the sensor application for analyses [19]. Graphene-based paints include antistatic, conductive ink [20], electromagnetic-interference
Fig. 1 Article number per year, as recorded Web of Science (http://apps.webofknowledge. com), from 1997 to August 2018 received using the keyword "nanofluid" in the article topic

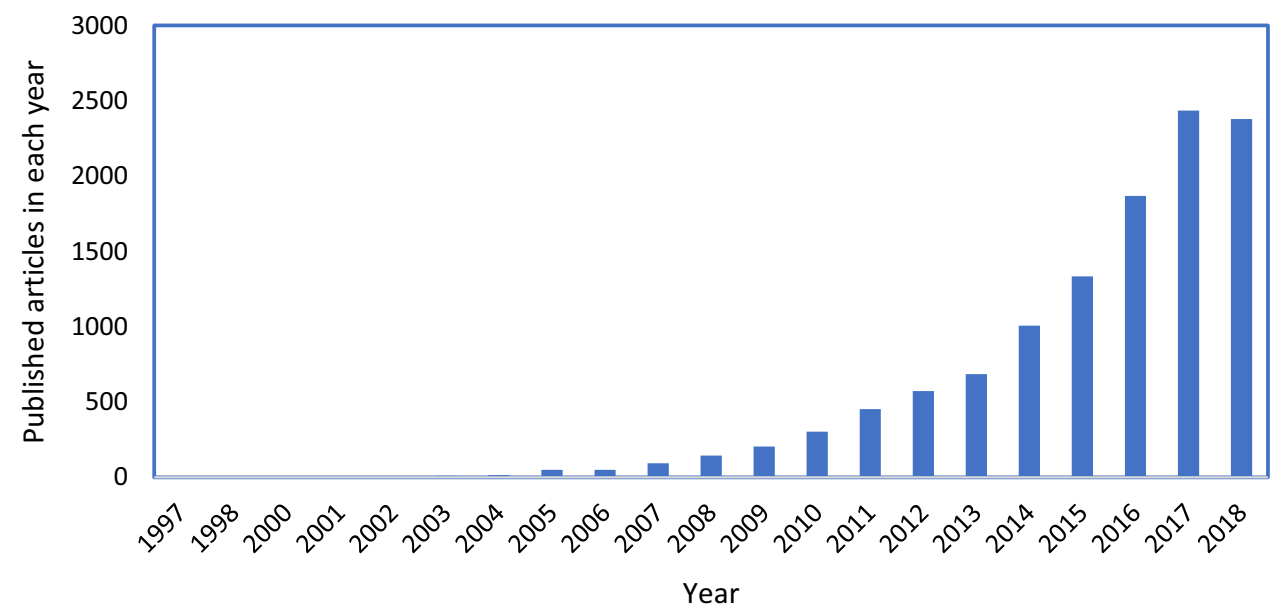


shielding [21], and gas barrier [22]. Because the production technology of graphene is simple and reasonably developed, and the development of chemical derivatives of graphene to control the product's optical opacity and conductivity would be conducted, graphene is so attractive for researchers and companies. Figure 6 outlines various types of synthesis routes along with general applications in modern-day life.

In Table 1, there are several techniques, by which single- and few-layered graphenes have been produced. These techniques are able to be broadly classified into exfoliation, chemical synthesis, pyrolysis, CVD, see Fig. 3.
Fig. 2 Article number per year, as recorded Web of Science (http://apps.webofknowledge. com), from 2009 to August 2018 received using the keywords "nanofluid" and "graphene" in the article topic
Fig. 3 Oxidation process of graphite and reduction process of GO [10]
Table 1 Synthesis of singleand few-layered graphene [23]
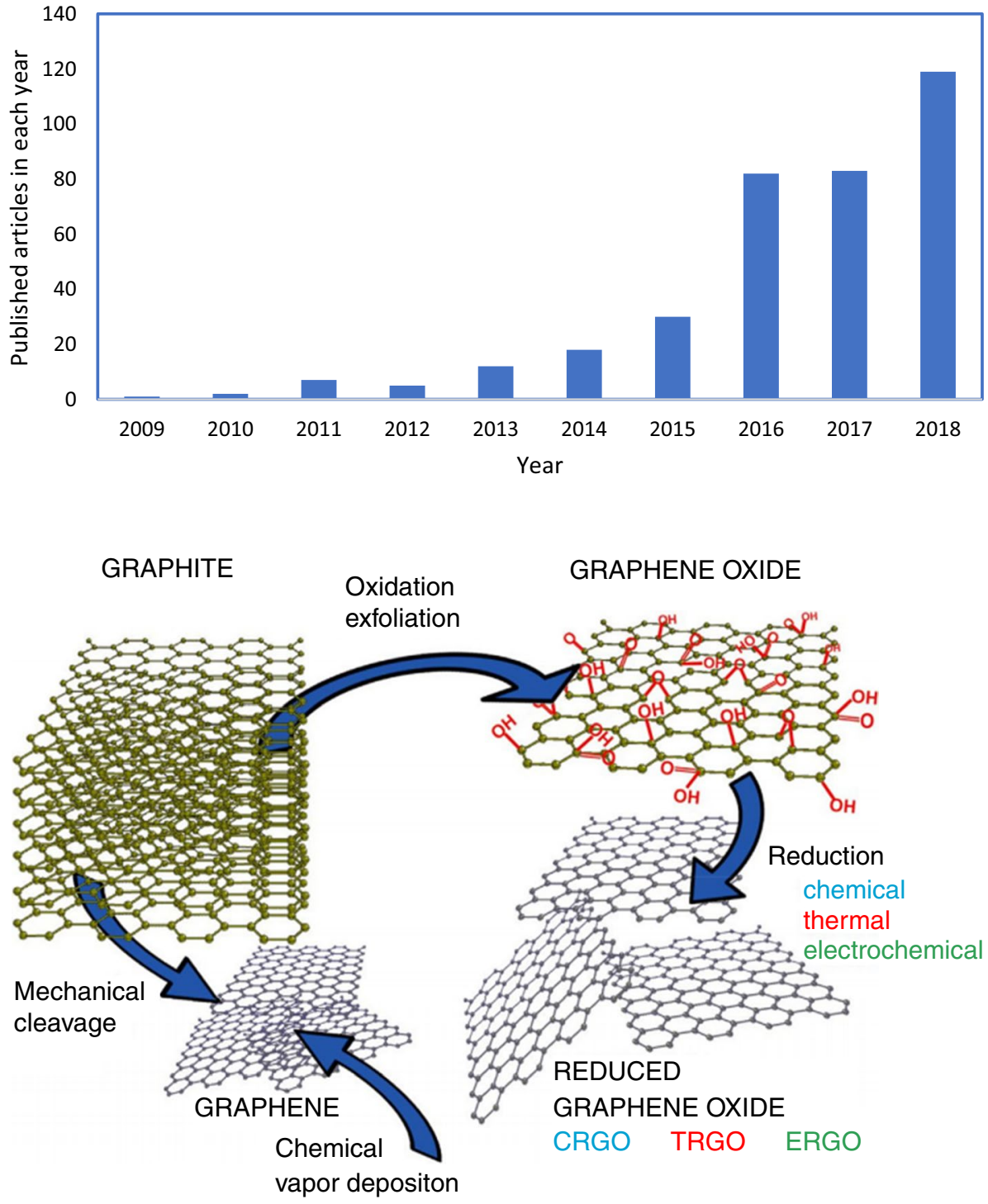
CVD is a hopeful, cheap, and readily accessible approach for the deposition of moderately high-quality graphene [24]. The principle of CVD is connecting and depositing molecules of volatile gas onto a transition metal substrate. There are 2 types of CVD graphene growth as conducting through surface catalysis or carbon segregation ways depending on the metal, respectively, at high and low temperatures in the process [25]. For the surface-catalyzed technique, the process occurs in a reaction chamber, in which graphene is created upon the surface of the substrate by the high-temperature decomposition of carbon-containing gases and therefore the waste gases are taken out. Growth can be represented as "self-limiting" formation of great area monolayer graphene owing to low carbon solubility in metal. In case of segregation, graphene is produced by way of the diffusion of carbon that is dissolved within the majority metal to the metal surface, which usually happens upon cooling for the reason that the solubility of carbon is lower in metals at lower temperatures. The quantity of graphene layers is synthesized by segregation depending upon numerous factors: the quantity of dissolved carbon and also the cooling rate [26, 27]. The optimal condition for the CVD process depends on the metal and other various factors ( $p, T$, etc.) affecting graphene quality and thickness. Additionally, the power of graphene-metal interaction might affect the degree of graphene rippling and graphene sensitivity. Besides manufacturing graphene layers, CVD can be utilized to synthesize GNSs. The advantage of the substrate-free method is that the process does not require particular substrates or the removal of graphene from the substrate. Moreover, graphene can be made via continuous processing, as a result of the collected material outside the chamber.

The mechanical or micromechanical exfoliation method is the first acknowledged technique of graphene synthesis in graphene's history [28]. This is still a significant method for producing superior graphene for purposes of study because it gives amazing graphene films $(5-10 \mu \mathrm{m})$. Nonetheless, the rough thickness of layers is produced by the technique and the cost of production is high because of low yield that makes this technique unusable for large-scale production. This method is a top-down strategy in nanotechnology, by which a graphene precursor is produced upon the surface of the layered structure materials forming graphene sheets. Graphite is a stack of mono-atomic graphene which can be separated into individual sheets of graphene by overcoming van der Waals forces [29]. Graphene sheets of various thicknesses can be produced through mechanical exfoliation or by stripping off layers from graphitic materials, for example, highly ordered pyrolytic graphite, so-called HOPG, natural graphite, or single-crystal graphite [30-34]. This method can be performed by using various agents as ultrasonication [35], scotch tape [28], electric field [36], etc. Graphene flakes produced by these methods are often described by Raman spectroscopy, optical microscopy, and AFM. AFM analysis is performed on exfoliated graphene to evaluate its thickness and layer number. Optical microscopy is another well-known method for identifying single-layer graphene. The micromechanical exfoliation method is the most common method after the discovery of graphene in order to produce superior, defect-free graphene. In the method, graphene is isolated from a graphite crystal by utilizing "scotch tape". Multiplelayer graphene stays upon the tape after being peeled off graphite. Repeatedly, the multiple-layer graphene is separated into a few pieces of few-layer graphene. Accordingly, the tape is joined to the acetone substrate for disconnecting the tape. In the end, with an unused tape, one last peeling is carried out. The produced flakes are different in thickness and size, where the sizes are from $\mathrm{nm}$ to several tens of $\mu \mathrm{m}$ for single-layer graphene. In fact, it is difficult to get a higher quantity of graphene by the technique, not even considering the absence of sustainable flakes. The trouble of this method is low production yield; however, the prepared graphene's quality is very high with no defects. The mechanical exfoliation method needs to make a higher production yield, with defect-free and high-purity graphene for the nanotechnology field.

On a fundamental level, ball milling is a sub-type of mechanical exfoliation; however, numerous varieties of this technique were developed, so this technique should be considered separately. Figure 4 illustrates the mechanical exfoliation of graphene via ball milling. Ball milling, a common method for generating shear force, has been utilized to mix and reduce the size of particles for a long time. Researchers have utilized this particle size reduction method to exfoliate graphene from graphite, occasionally utilizing magnetic assistance. This provides filtering the metallic particles in the precursors and utilizing solvent [38] or chemical

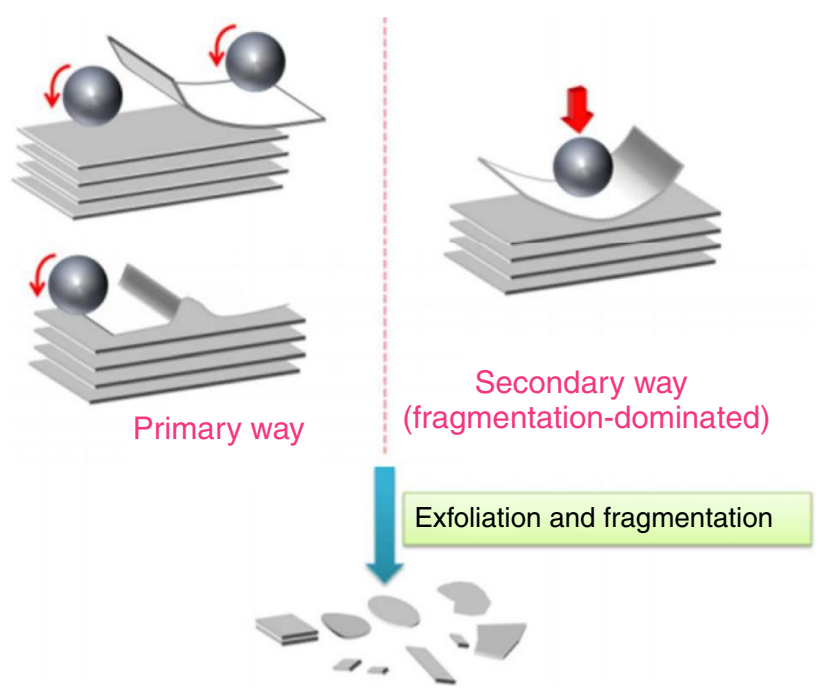

Fig. 4 Scheme for the mechanical exfoliation via ball milling [37] 
assistance [39, 40], which provides the prevention of the sheets from stacking again by utilizing chemical interaction, for example, $\pi-\pi$ (see Fig. 5). This method provides a few layers of graphene, high generation efficiency, and a larger surface area of graphene.

Superior, nonoxidized graphite and graphene flakes may be produced by sonication [42]. For sonication technique, ultrasonic power is utilized for isolating graphene sheets heaped up in a precursor. However, the technique needs lots of energy because sonication is the only power source and this should be considered when extending this technique [43]. Additionally, removing impurities is an issue that happens during this procedure. Solvent support sonication is a simple adjustment of sonication technique with the help of a solvent as $\mathrm{N}$-methyl-pyrrolidone, triethylamine, etc., in which graphene can be isolated from graphite with centrifugation [42]. When utilizing the solvent support systems, graphene can stack again after sonication due to van der Waals forces. For preventing from these issues, surfactants are taken to the solution before sonication; thus, the graphene layers could not be folded. This technique can be utilized to produce graphene layers from graphite without chemical change.

Parvez and colleagues presented a fascinating technique for exfoliating graphene from graphite by utilizing the electrochemical technique. $0.1 \mathrm{M} \mathrm{H}_{2} \mathrm{SO}_{4}$ solution was used as an electrolyte, while platinum wire as cathode and graphite flakes as an anode. A $+10 \mathrm{~V}$ charge was utilized for the system, and the graphite flakes started to dissolve in the solution. The voltage was discarded after $2 \mathrm{~min}$, and they collected exfoliated graphite material using vacuum filtration. For the removal of residual acid content, the sample was washed with DI several times. Finally, the sample powder was dispersed in $N, N^{\prime}$-dimethylformamide, creating exfoliated graphene sheets. The production yield was greater than $60 \%$ of the starting graphite's total amount [44]. Lu et al. showed one-pot synthesis for various types of nanocarbons, including graphene by the exfoliation of graphite in ionic liquids. They used a water-miscible ionic liquid 1-butyl-3-methylimidazolium tetrafluoroborate $[\mathrm{BMIm}]\left[\mathrm{BF}_{4}\right]$ with water at various fractions as an electrolyte to produce graphene from graphite by electrochemical technique. Static potentials from 1.5 to $15 \mathrm{~V}$ have been applied to two electrodes using DC power supply. Exfoliating particles were cleaned with water and then ethanol to obtain a neutral pH [45] (Fig. 6).

Pyrolysis provides the simplicity of the procedure and can be extended for production. Nonetheless, the production yield is poor, and the final product has impurities. In this technique, Choucair et al. heated 1: 1 molar ratio of sodium $(2 \mathrm{~g})$ and ethanol $(5 \mathrm{~mL})$ in a closed reactor at $220{ }^{\circ} \mathrm{C}$ for $72 \mathrm{~h}$ to obtain the solid solvothermal productgraphene precursors, which was then quickly pyrolyzed, and the remaining product was cleaned using DI $(100 \mathrm{~mL})$. Then, the suspended sample was vacuum-filtered and dried in a vacuum chamber at $100{ }^{\circ} \mathrm{C}$ for $24 \mathrm{~h}$. The technique can approximately yield graphene $0.1 \mathrm{~g}$ per $1 \mathrm{~mL}$ of ethanol—usually $0.5 \mathrm{~g}$ per reaction [47]. Pyrolysis has also been utilized for producing carbon forms for high-energy supercapacitor applications. Interestingly, their origin was biomass and their characteristics were similar to graphene [48].

Graphite is capable of being reduced to graphene through intercalation as well. Between the graphite interlayer space, various chemical species can be added to obtain GIC. The interlayer range of graphite is significantly increased because of the presence of these intercalations between graphite layers. This also strongly affects the properties of graphene for the reason that the increase in the distance changes the electronic coupling between the graphene layers. Thus, various interstitial spaces can lead to GIC having different properties that can be utilized for applications that focus on electrical, thermal, and magnetic characteristics [49]. Lee et al. [50] researched the impacts of intercalation on capacitance in the electrode. They investigated the electrode capacitance by cyclic voltammetry and galvanostatic charge/discharge test and reported the electroconductivity enhancement of $\mathrm{MnO}_{2}$ because of the presence of GIC.
Fig. 5 Mechanical exfoliation of carbon nanofibers into graphene via ball milling by using melamine [41]

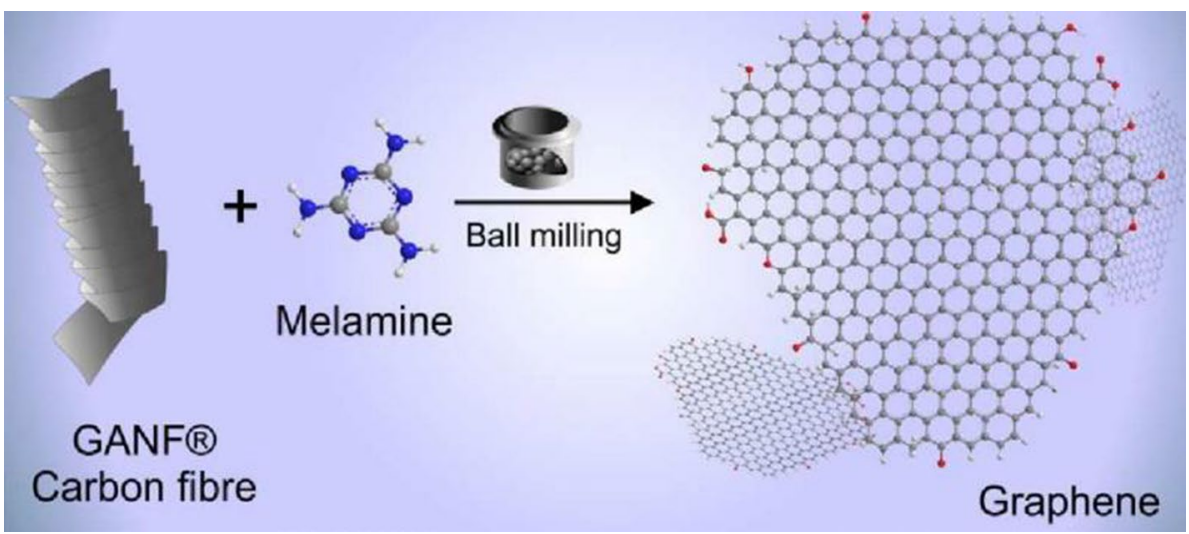




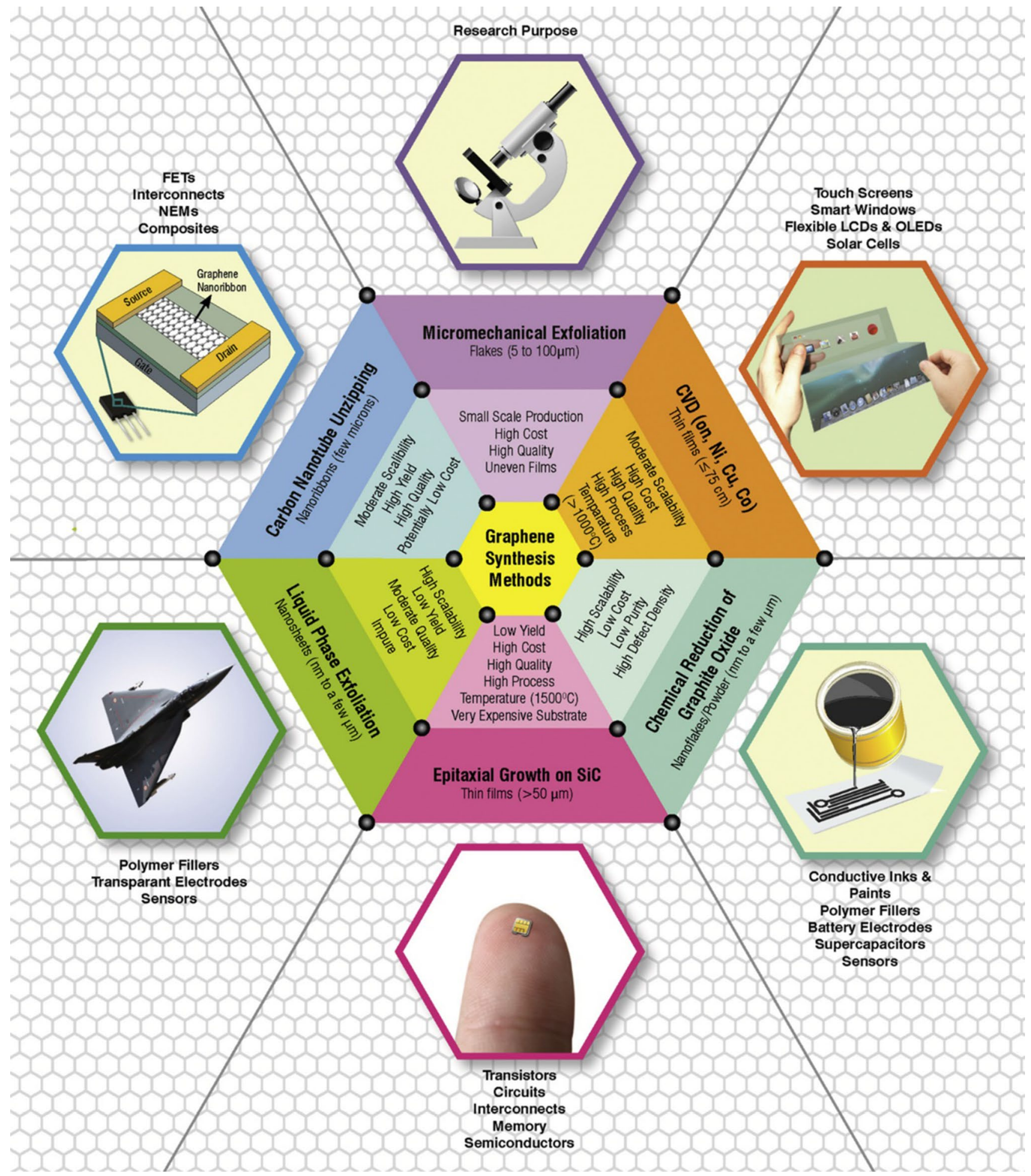

Fig. 6 Scheme of various popular synthesis methods of graphene along with their respective features and their current and prospective applications [46]

The graphene nanopowders/flakes, sized from $\mathrm{nm}$ to $\mu \mathrm{m}$, can be produced by chemical reduction of GIO, which is one kind of the conventional procedures for the synthesis of graphene in huge amount. Graphene produced by this technique is good for use in battery electrodes, polymer fillers, supercapacitors, sensors, conductive inks, and paints, etc. 
GO is able to be exfoliated by sonication in a solvent; however, the obtained material is insulated; therefore, it can be reduced to reestablish its conductivity. The reduction can be done by treating it chemically or thermally [51]. Also, rapid heating has been considered as a possible solution bringing about significant yields of dispersed carbon powders with a few percents of carbon flakes [52]. In addition, by dispersing oxidized graphite, then chemically treating water, and utilizing papermaking methods, monolayer flakes in the form of a very powerful bonding single sheet can be produced. Chemical techniques enable to produce graphene of low purity with high-density surface defects at lower temperatures and costs.

Another technique for producing graphene is that graphene can be grown quickly and continuously in atmospheric plasmas without substrates, acids, or catalysts. The plasma reactor owns a vacuum used for the removal of atmospheric and surface contaminants, the rise of grain size needs more time and energy and, thus, it increases the cost of this method. The single-step process is the transfer of carbon-containing materials into an Ar plasma, which breaks down organic materials into the atoms because of the high energies of heavy particles and electrons. Graphene, $\mathrm{H}_{2}$, and $\mathrm{CO}$ are formed from the combination of these reactive parts in the high-temperature condition of the plasma sparkle. The produced graphene in this method is highly ordered, pure, and stable under ambient conditions [53].

Askari et al. [54] produced nanoporous graphene by using a CVD method in a catalytic basis. They heated the furnace up to $900-1100^{\circ} \mathrm{C}$. They carried out the reaction by utilizing $\mathrm{CH}_{4}$ as the carbon source and $\mathrm{H}_{2}$ as the carrier gas in a ratio of $4: 1$; then, they stirred the product in $\mathrm{HCl}$ solution and washed it several times with DW. Naghash et al. [55] also utilized this method with a metal oxide catalyst.

Another method of producing graphene which has received considerable attention is exfoliation and reduction or heating of GIO. Ramón-Raygoza et al. [56] used this method to produce multilayer graphene and multilayer graphene impregnated with copper. These materials were used in preparing nanofluids for commercial motor oil.

\section{Preparation of GO}

Flake graphite is the most popular source of graphite and a naturally occurring mineral. The flake graphite is purified by removal of the heteroatomic contamination. The various oxidation techniques of graphite into GO through a slight modification to reported classical methods using graphite, acids, and oxidizing chemicals are given in Figs. 7 and 8. In 1859 , the synthesis of GO was first demonstrated by Brodie by adding a fraction of potassium chlorate $\left(\mathrm{KClO}_{3}\right)$ to a slurry of graphite in fuming nitric acid $\left(\mathrm{HNO}_{3}\right)$ [59].

Staudenmaier improved on Brodie's method in 1898 by utilization of a mixture of concentrated fuming $\mathrm{HNO}_{3}$ and
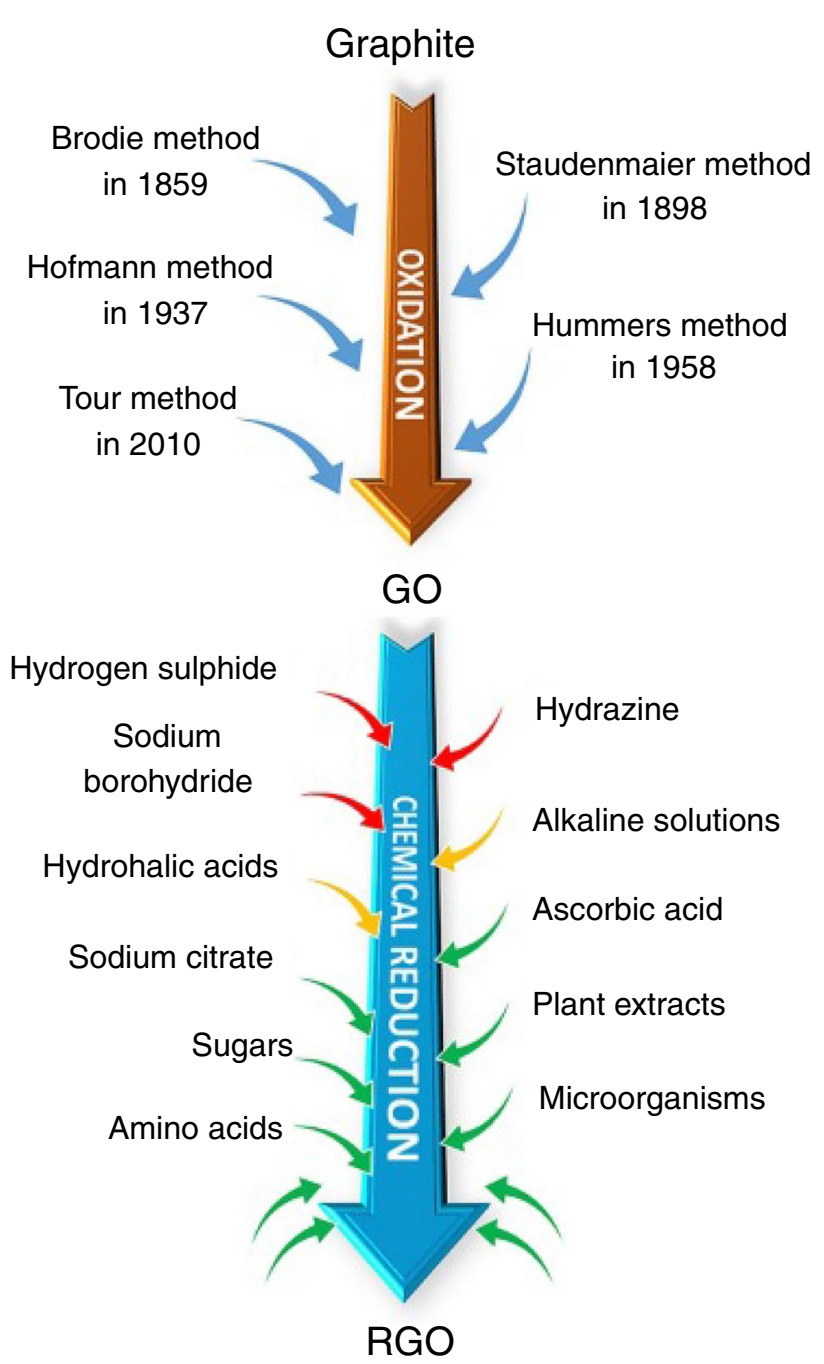

Fig. 7 Scheme for the various oxidation techniques of graphite into $\mathrm{GO}$ and the chemical reduction of GO into rGO [57]

sulfuric acid $\left(\mathrm{H}_{2} \mathrm{SO}_{4}\right)$ followed by adding gradually $\mathrm{KClO}_{3}$ to the reaction mixture [60]. A simple and revised protocol was provided by this small change in the procedure for the production of highly oxidized GO. Nevertheless, this technique created $1 \mathrm{~g}$ of $\mathrm{GO}$ to $10 \mathrm{~g}$ of $\mathrm{KClO}_{3}$ and had a lot of hazards.

Hofmann et al. [61, 62] produced GO by using concentrated $\mathrm{HNO}_{3}$ in combination with concentrated $\mathrm{H}_{2} \mathrm{SO}_{4}$ and $\mathrm{KClO}_{3}$ in 1937.

Due to the utilization of concentrated $\mathrm{HNO}_{3}$ and $\mathrm{H}_{2} \mathrm{SO}_{4}$, the production of GO was dangerous and slow, and $\mathrm{HM}$ was developed in 1958 as a quicker, safer, and more efficient technique [63-65] by using potassium permanganate $\left(\mathrm{KMnO}_{4}\right)$ and sodium nitrate $\left(\mathrm{NaNO}_{3}\right)$ in concentrated $\mathrm{H}_{2} \mathrm{SO}_{4}$. The obtained suspension was diluted with DW. Then, they added hydrogen peroxide $\left(\mathrm{H}_{2} \mathrm{O}_{2}\right)$ to eliminate manganese from the suspension and to get a higher oxidation 
Fig. 8 Schematic procedure for Brodie, Staudenmaier, Hofmann, and HM ( $c$ concentrated, $f$ fuming) [58]

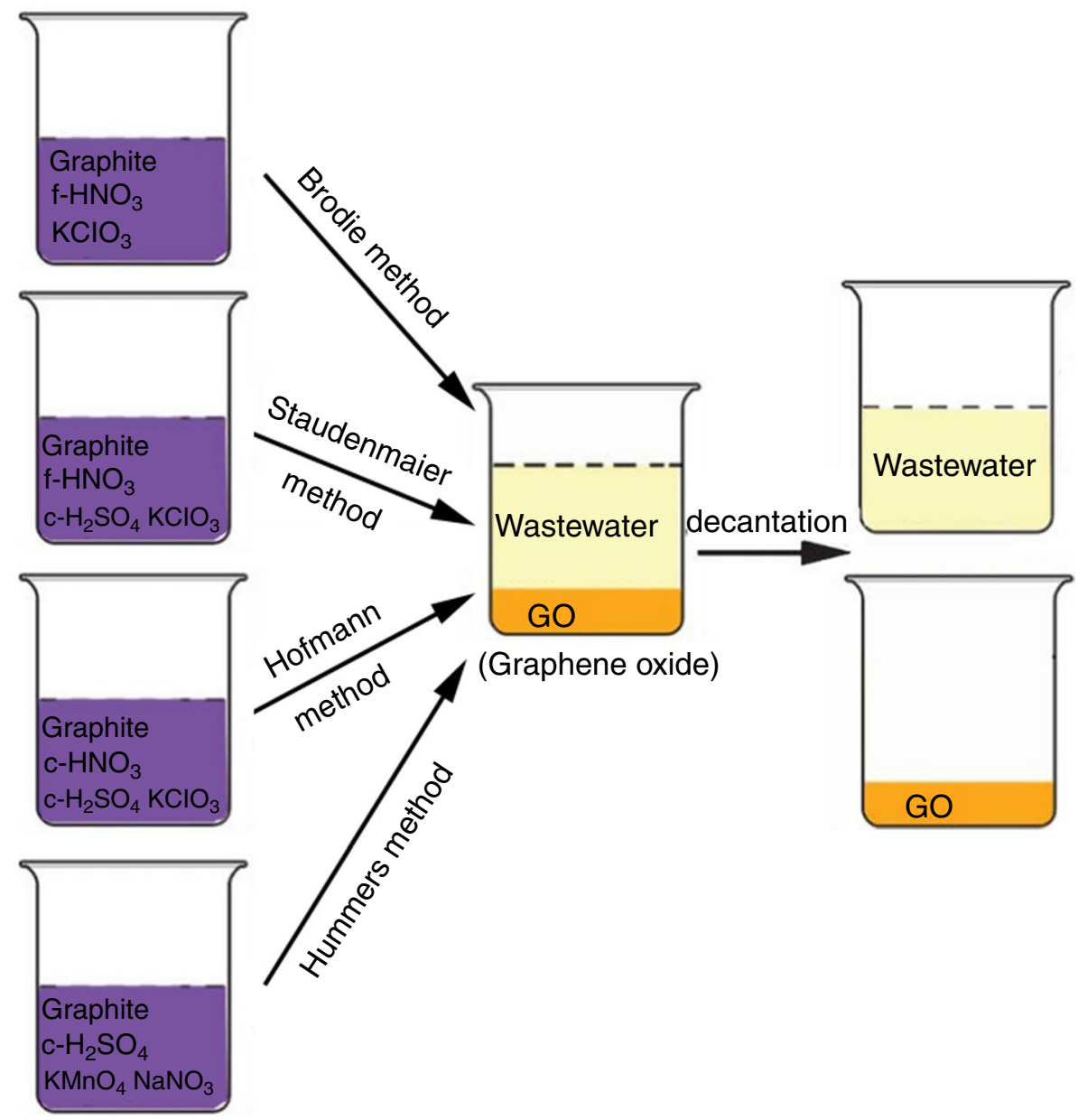

degree. They filtered the sample and washed with warm water. The disadvantage of this technique is the time-consuming of the separation and purification process. MHM has been used by several research groups for the synthesis of GO [66-69].

An improvement of HM was performed by the Tour's group in 2010 [70]. Sodium nitrate was substituted with phosphoric acid in 9:1 mixture of concentrated $\mathrm{H}_{2} \mathrm{SO}_{4} /$ $\mathrm{H}_{3} \mathrm{PO}_{4}$ and the amount of $\mathrm{KMnO}_{4}$ increased. This method does not produce toxic gases, and another advantage is easy temperature control. Some improved synthesis methods involve oxidation of graphite by changing the amount of $\mathrm{KMnO}_{4}$ [71] or using benzoyl peroxide [72] or Jone's reagent [73] (see Fig. 9).

Esmaeili-Faraj et al. [74] prepared exfoliated GO by modified Staudenmaier method. According to that, they oxidized the graphite nanoparticles and stirred in a mixture of $\mathrm{H}_{2} \mathrm{SO}_{4}, \mathrm{HNO}_{3}$, and $\mathrm{KClO}_{3}$ for approximately $100 \mathrm{~h}$. Then, they rinsed GIO with hydrochloric acid and then washed with water. After drying, they dispersed GIO in water and put in an ultrasonic bath to exfoliated GO. Ramón-Raygoza et al. [56] also produced nanoparticles with this modified Staudenmaier method.
Anin Vinccely et al. [75], Luo et al. [76], Esfahani et al. [77], Kim et al. [78], and M. Mirzaei and A. Azimi [79] produced GO same as other investigators with MHM.

Mehrali et al. [80] used an SHM to synthesize GO and then introduced a technique for preparing NDG by a hydrothermal process with GO as a raw material in an ammonia solution. First, they sonicated a mixture of GO and water and adjusted the $\mathrm{pH}$ of the solution with ammonia. Then, they treated hydrothermally the homogeneous solution in a Teflon-lined autoclave at $160^{\circ} \mathrm{C}$. They collected a black woolly precipitate by centrifugation and cleaned with DI. Finally, they dried the obtained NDG under a vacuum.

\section{Preparation of rGO}

rGO is created by reducing GO with many techniques. There are 3 main types: thermal reduction, chemical reduction, and electrochemical reduction [81], which are summarized in Fig. 3.

Reducing GO via chemical reduction may be a scalable technique; however, unluckily the operation has usually brought approximately poor yields and utilized highly toxic materials like hydrazine [82]. Compared to the GO 
Fig. 9 Schematic representation of the oxidation procedures with graphite flakes as a starting material. Under-oxidized hydrophobic carbon material recovered during the purification of improved, Hummers, and Hummers modified GO [70]

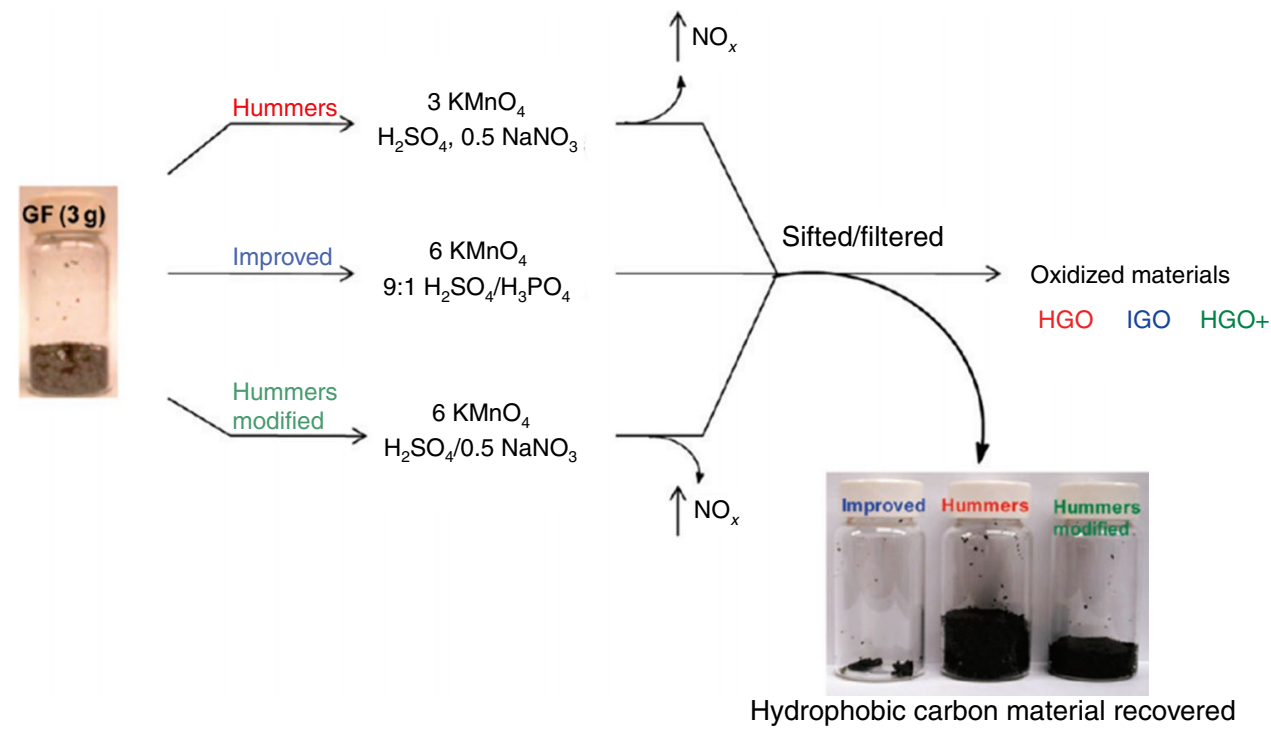

precursor, rGO created by this technique typically presents a substandard EC and surface area (see Fig. 7).

Thermally reducing GO at temperatures of $1000{ }^{\circ} \mathrm{C}$ or higher produces rGO that has been shown to have a high surface area, which indicates that it is similar to pristine graphene even. Unfortunately, the intense heating method damages the structure of the graphene layers as high pressure builds up and $\mathrm{CO}_{2}$ emission is discharged [83, 84]. This causes a considerable reduction within the overall mass, vacancies of the GO as well and influences the mechanical strength of the rGO. The benefits of the method are simplicity, nonchemical, and low cost [85] (see Fig. 10).

An electrochemical reduction may eventually be suitable for the huge scale production of rGO. rGO produced by this technique has top quality, almost consistent in terms of structure to pristine graphene, in fact. By many ways, rGO compound can be functionalized in numerous applications. By treating rGO, the properties of the compound to suit business applications can be enhanced such as high TC. Another benefit of this process is no toxic waste. In Fig. 11, rGO can be produced by the electrochemical reduction via two different ways: the one-step and two-step approach. For the one-step electrochemical approach, from an aqueous colloidal suspension GO sheets are directly reduced in the presence of buffer electrolytes for producing the electrochemically rGO thin films on an electrode surface. This process can be carried out with linear sweep voltammetry [87], cyclic voltammetry [88, 89], or at a constant potential mode $[87,90]$ at room temperature. For the two-step electrochemical method, a thin film of GO is firstly placed on the electrode surface that plays a role as a substrate and then is dried out to produce GO-coated electrode. This electrode is subsequently given to electrochemical reduction in the attendance of a supporting electrolyte or buffer for the production of rGO films [91].

A complete review of graphene and graphene derivatives-based nanofluids is presented in Table 2. Recently, in most of the nanofluid experimental researches, the nanoparticles have been supplied by the manufacturer.
Fig. 10 Schematic procedure for the synthesis of thermally rGO from graphite. Graphite is oxidized to GO [86]

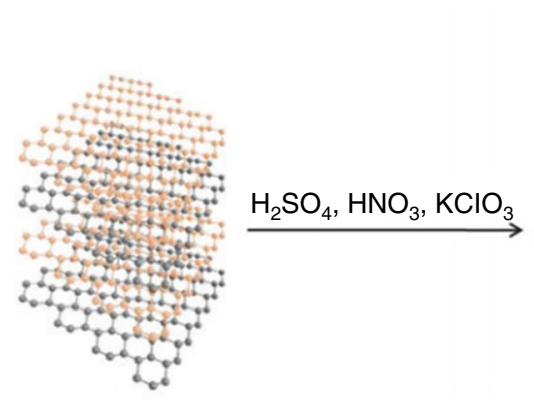

Graphite
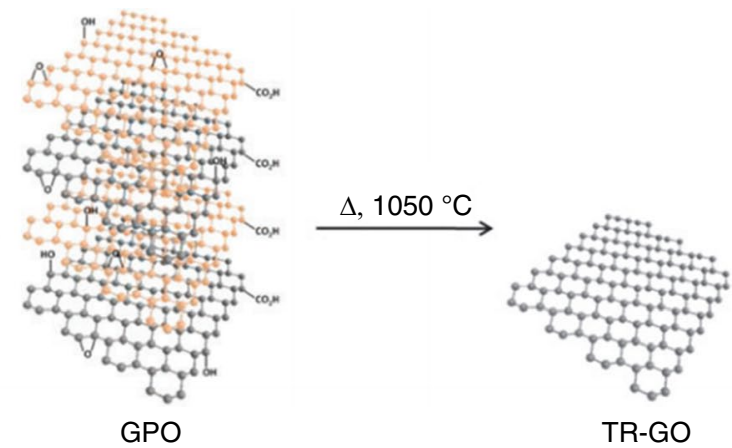

TR-GO 
Fig. 11 Schematic representation for electrochemical reduction approach to the production of electrochemically rGO [91]

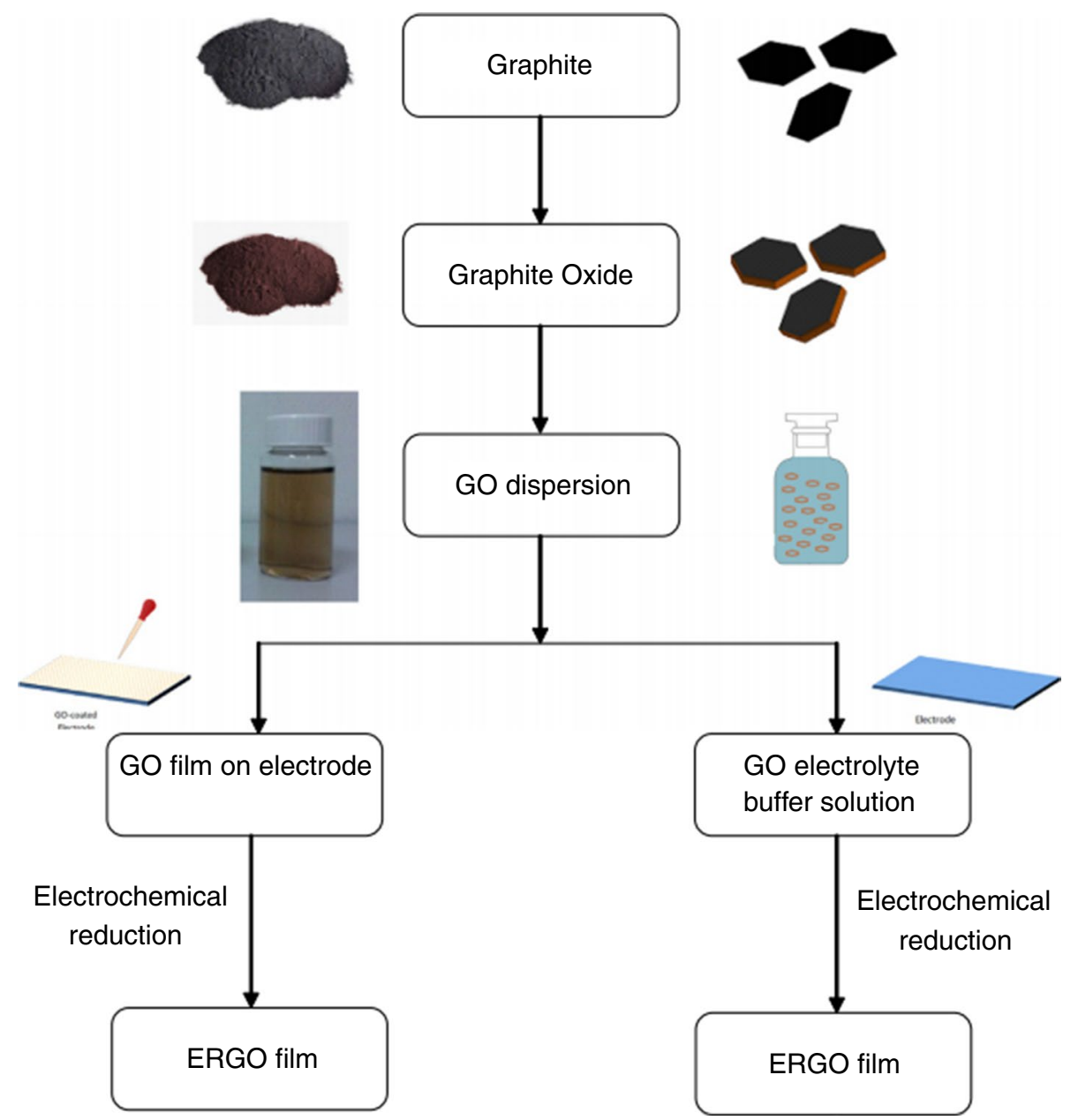

\section{Preparation of nanofluids}

The preparation of nanofluids is the first and main part of the exploratory investigation on nanofluids. It is not just a simple operation of mixing the nanoparticles into the BF. The minimization of the particle agglomeration is an advantage of the one-step synthesis technique. But the strict condition is required for such a process. The two-step preparation process [201] is still popular in research articles as the most commercial process for the production of nanofluids because of its simplicity. Stabilization and proper mixing are required to get nanofluids with homogeneously dispersed nanoparticles due to strong van der Waals force among nanoparticles. The most common technique is shown in Fig. 12.

A higher shear mixing or ultrasonic vibrator is mostly used to homogenize nanopowders with BFs. In order to reduce particle agglomeration, the regular use of ultrasonication or stirring is required. In most research articles, water is used for BF. Jia et al. [131] used the two-step technique to produce GNFs of DW and surfactant. Tharayil et al. [133], Iranmanesh et al. [152] used commercially available GNSs to prepare nanofluids of water without surfactant by sonication. Sarsam et al. [135], Sathishkumar et al. [138], Selvam et al. [153], and Abd Elhafez et al. [155] prepared GNPs nanofluids of water with different surfactants, while Vakili et al. [136], Khosrojerdi et al. [150], and Sadeghinezhad et al. [151] used without surfactant. By HM or MHMs, Shende et al. [64], Akhavan-Zanjani et al. [65], Anin Vincely et al. [75], Esfahani et al. [77], Kim et al. [78] produced GONFs of water by sonication or stirring.

Yu et al. [93] exhibited a chemical method for producing GONs-based nanofluids, which was obtained by exfoliation of GO in anhydrous ethanol. The collected nanoparticles were loose brown and dispersed in EG without surfactants. Aside from the utilization of the ultrasonic device, some various methods, for example, functionalized graphene sheets, were presented by several other authors. MartinGallego et al. [202] synthesized graphene sheets in-house the rapid thermal expansion of $\mathrm{GO}$ at $1000{ }^{\circ} \mathrm{C}$ under an inert atmosphere. Carbon material was produced with high surface zone comprising of graphene layers with residue carbonyl, hydroxyl, and epoxy groups. Baby and Sundara [97] presented a technique for preparing the copper oxidedecorated graphene-dispersed nanofluids. Firstly, carboxyl 
Table 2 Outline of several synthesized GNFs

\begin{tabular}{|c|c|c|c|c|}
\hline References & Base fluid & Material & Synthesis method & Loading \\
\hline [92] & DW & $\mathrm{GR}+\mathrm{GO}$ & МHM & 0.001 vol $\%$ \\
\hline [93] & EG & GONs & MHM & $1-5$ vol $\%$ \\
\hline [94] & EG & GONs & MHM & $0.01-11.03$ mass $\%$ \\
\hline [95] & EG & GONs & МHM & $0.01-0.05$ vol $\%$ \\
\hline [96] & $\mathrm{EG}+\mathrm{DW}$ & GR & МHM & $0.005-0.056 \mathrm{vol} \%$ \\
\hline [97] & $\mathrm{EG}+\mathrm{DI}$ & Metal oxide-decorated GR & Copper oxide-decorated GR & $0.005-0.056$ vol $\%$ \\
\hline [98] & $\begin{array}{l}\text { EG } \\
\text { DI }\end{array}$ & GR & Hydrogen exfoliated GR & $\begin{array}{l}0.005-0.05 \text { vol } \% \\
0.05-0.08 \text { vol } \%\end{array}$ \\
\hline$[7]$ & EG & GNS & МHM & $0.01-11.03$ mass $\%$ \\
\hline [99] & DI & Silver NPs-decorated GR & MHM to prepare the GO & $0.005-0.056 \mathrm{vol} \%$ \\
\hline [100] & $\mathrm{EG}+\mathrm{DI}$ & GNS & MHM & $\begin{array}{l}0.008-0.138 \text { vol } \% \\
0.008-0.138 \text { vol } \%\end{array}$ \\
\hline [101] & DW & GO & MHM & 0.0001 vol $\%$ \\
\hline [102] & DW & GO & MHM & $0.0001 \mathrm{vol} \%$ \\
\hline [103] & DW & Polydispersed GNS & MHM, then synthesized & 0.5 mass $\%$ \\
\hline [104] & DW & Functionalized GR & CVD & $0.01-0.05$ mass $\%$ \\
\hline [105] & 70 vol $\%$ EG + 30 vol $\%$ DW & GR & MHM, then synthesized & 0.395 vol $\%$ \\
\hline$[106]$ & DI & Silver NP-decorated MWCNTs GR & MHM, then synthesized & $0.005-0.04$ vol $\%$ \\
\hline [107] & DW & GR & MHM & $0.005-0.02$ vol $\%$ \\
\hline [108] & DW & GONs & SBM & $0.0001-0.0002$ mass $\%$ \\
\hline$[3]$ & DW & GNPs & SBM & $0.025-0.1$ mass $\%$ \\
\hline [109] & DW & GR & MHM & $0.03-0.06$ mass $\%$ \\
\hline [110] & DW & GR & MHM & 0.01 vol\% \\
\hline [111] & DW & $\begin{array}{l}\text { Functionalized pristine GR/metal } \\
\text { NP hybrid }\end{array}$ & MHM, then synthesized & $1-3 \mathrm{G}$ (generation) \\
\hline [112] & DW & GR & SBM, then oxidized by acid & $0.001-0.01$ vol $\%$ \\
\hline [113] & DW + different SUR & Solvent-free GR & $\begin{array}{l}\text { MHM, then synthesized the } \\
\text { material }\end{array}$ & $10 \mathrm{mg} \mathrm{mL}^{-1}$ \\
\hline [114] & DW + different SUR & NDG & MHM, then synthesized & $0.01-0.06$ mass $\%$ \\
\hline$[115]$ & DI & GO & MHM & $0.05-0.25$ mass $\%$ \\
\hline [116] & DW & Exfoliated GO & MHM, then synthesized & $0.005-0.025$ mass $\%$ \\
\hline [117] & DW & $\mathrm{SiO}_{2}$-coated graphene & MHM, then synthesized & 0.1 mass $\%$ \\
\hline [118] & DW & GO & MHM, then synthesized & $0.0001-0.0006$ mass $\%$ \\
\hline [119] & DW & $\mathrm{GO}+$ its hybrid complexes & MHM, then synthesized & 0.05 mass $\%$ \\
\hline$[120]$ & [HMIM]BF4 & GR & SBM & $0.0005-0.01$ mass $\%$ \\
\hline$[121]$ & DW & GO/GNPs & MHM & $0.0125-0.075$ mass $\%$ \\
\hline [122] & DW & GO + its hybrid complexes & MHM & 0.05 mass $\%$ \\
\hline [123] & Acetone & GR & SBM & $0.05-0.09$ vol $\%$ \\
\hline [124] & $\mathrm{DW}+\mathrm{SUR}$ & MWCNTs + GR & SBM & $\begin{array}{l}\text { Mass ratios: } 1 / 3,3 / 1 \\
1 / 1,1 / 2,2 / 1\end{array}$ \\
\hline [125] & DI & Silver oxide + GO & SBM & $0.01-0.1$ mass $\%$ \\
\hline [126] & DW & GONs & SBM & $0.005-0.1$ mass $\%$ \\
\hline$[127]$ & DW & $\mathrm{CNTs}+\mathrm{GR}$ & SBM & $0.1 \mathrm{vol} \%$ \\
\hline [128] & DW & GR & CVD-grown graphene & $0.05-0.1$ mass $\%$ \\
\hline [129] & Silicone oil & Functionalized GNS & MHM, then synthesized & $0.0-0.07$ mass $\%$ \\
\hline$[130]$ & $\begin{array}{l}\text { EG } \\
\text { DI }\end{array}$ & NDG-MNT & HM, then CVD & $\begin{array}{l}0.005-0.03 \text { vol } \% \\
0.005-0.02 \text { vol } \%\end{array}$ \\
\hline [131] & $\mathrm{DW}+\mathrm{SUR}$ & GNSs & SBM & 0.05 mass $\%$ \\
\hline [132] & Kerosene + SUR & GNPs & SBM & $0.005-0.2$ mass $\%$ \\
\hline [133] & DW & GNSs & SBM & $0.003-0.009$ mass $\%$ \\
\hline [134] & $\mathrm{DW}+\mathrm{SUR}$ & GR & SBM & $0.05-0.15$ mass $\%$ \\
\hline
\end{tabular}


Table 2 (continued)

\begin{tabular}{|c|c|c|c|c|}
\hline References & Base fluid & Material & Synthesis method & Loading \\
\hline$[135]$ & DW + different SUR & GNPs & SBM & 0.1 mass $\%$ \\
\hline$[75]$ & DW & GO & MHM & $0.005-0.02$ mass $\%$ \\
\hline [136] & DW & GNPs & SBM & $0.0005-0.001$ mass $\%$ \\
\hline$[137]$ & DW & $\begin{array}{l}\text { Dry sulfonic acid-functionalized } \\
\text { GNPs }\end{array}$ & SBM & $0.25-1.00$ mass $\%$ \\
\hline$[138]$ & $\mathrm{DW}+\mathrm{SUR}$ & GNPs & SBM & $0.3-1.2$ mass $\%$ \\
\hline [139] & $\mathrm{DW}+\mathrm{SUR}$ & NDG & SBM & $0.01-0.06$ mass $\%$ \\
\hline$[140]$ & DW & $\begin{array}{l}\text { GR-substrate, } \mathrm{Al}_{2} \mathrm{O}_{3}, \mathrm{SiO}_{2} \text {-sur- } \\
\text { faces }\end{array}$ & SBM & $0.1-10$ vol $\%$ \\
\hline$[141]$ & DW & Triethanolamine-treated GNPs & SBM & $0.025-0.1$ mass $\%$ \\
\hline [76] & Oil+water & GO & MHM & $0.005-0.01$ mass $\%$ \\
\hline$[142]$ & DI & GNPs & SBM & $0.00025-0.005$ mass $\%$ \\
\hline$[143]$ & DI & GO nanoplatelets & SBM & $0.001-0.045$ mass $\%$ \\
\hline [77] & DI & GO & MHMs & $0.01-0.5$ mass $\%$ \\
\hline$[78]$ & DW & GO & MHMs & $0.01-0.03$ vol $\%$ \\
\hline$[65]$ & DW & GO & $\mathrm{HM}$ & $0.005-0.02$ vol\% \\
\hline$[54]$ & DW + SURs & MWCNTs + nanoporous GR & CVD & $0.1-0.3$ mass $\%$ \\
\hline$[144]$ & DW & GR + silver NPs & SBM & $0.2 / 0.4$ mass $\%$ \\
\hline$[80]$ & $\mathrm{DW}+\mathrm{SUR}$ & NDG & SHM, hydrothermal process & $0.01-0.06$ mass $\%$ \\
\hline$[145]$ & DW & Empty fruit bunch $+\mathrm{GO}$ & SHM & $0.02-0.06$ mass $\%$ \\
\hline [79] & DW & GO & MHMs & $0.02-0.12 \mathrm{vol} \%$ \\
\hline [146] & DW & Propylene glycol-treated GNPs & SBM & $0.05-0.25$ mass $\%$ \\
\hline$[147]$ & DW & Functionalized GNPs & SBM & $0.02-0.1$ mass $\%$ \\
\hline [148] & $\mathrm{DW}+\mathrm{SUR}$ & GR/MWCNT & SBM & 0.1 mass $\%$ \\
\hline$[74]$ & DW & Exfoliated GO & Modified Staudenmaier method & $0.005-0.025$ mass $\%$ \\
\hline [149] & $\mathrm{EG}+\mathrm{DI}$ & GNSs & SBM & $0.005-0.1$ mass $\%$ \\
\hline$[150]$ & DI & GNPs & SBM & $0.00025-0.005$ mass $\%$ \\
\hline [151] & DW & GNPs & SBM & $0.025-0.1$ mass $\%$ \\
\hline$[152]$ & DW & GNSs & SBM & $0.05-0.1$ mass $\%$ \\
\hline$[153]$ & $\mathrm{DI}-\mathrm{EG}+\mathrm{SUR}$ & GNPs & SBM & $0.1-0.5 \mathrm{vol} \%$ \\
\hline$[154]$ & $\mathrm{DW}+\mathrm{SUR}$ & Magnetic GR composites + GNPs & SBM & $0.025-0.1$ mass $\%$ \\
\hline$[155]$ & $\mathrm{DW}+\mathrm{SUR}$ & GNPs & SBM & $0.025-0.1$ mass $\%$ \\
\hline$[56]$ & Oil & GNPs & Modified Staudenmaier method & $0.5-2$ mass $\%$ \\
\hline [156] & Oil & GR & SBM & $0.02-1.0 \mathrm{mg} \mathrm{mL}^{-1}$ \\
\hline$[157]$ & Transformer oil & GR & SBM & $0.01-0.08$ mass $\%$ \\
\hline [158] & $\mathrm{EG}+$ water & $\begin{array}{l}\text { Sulfonic acid-functionalized GO } \\
\text { nanoplatelets }\end{array}$ & SBM & $0.1-0.5$ mass $\%$ \\
\hline$[64]$ & DI and EG & Few-layered rGO & HM & $0.005-0.03$ vol $\%$ \\
\hline [159] & DW & $\mathrm{rGO} / \mathrm{Fe}_{3} \mathrm{O}_{4}$ & SHMs & 0.5 mass $\%$ \\
\hline$[160]$ & $n$-butanol alcohol aqueous solution & GO & SBM & $0.008-0.12$ mass $\%$ \\
\hline$[161]$ & DW & Functionalized GNPs & SBM & $0.02-0.1$ mass $\%$ \\
\hline$[162]$ & EG and water + SUR & GNPs & SBM & $0.001-0.5$ vol $\%$ \\
\hline$[163]$ & Oil & GNSs & SBM & $0.0025-0.01$ mass $\%$ \\
\hline$[164]$ & DW + SUR & GR/MWCNT & SBM & $0.5-2.0$ vol $\%$ \\
\hline$[55]$ & $\mathrm{DI}+\mathrm{SUR}$ & Nanoporous GR & CVD & $0.025-0.1$ mass $\%$ \\
\hline$[66]$ & Kerosene & $\mathrm{Fe}_{3} \mathrm{O}_{4}$-decorated GR & MHM & $0.05-1.0$ mass $\%$ \\
\hline$[67]$ & Red wine & rGO & MHM & $1-4$ vol $\%$ \\
\hline$[165]$ & {$[\mathrm{BMIM}] \mathrm{BF}_{4}$ ionic liquid } & GI, SWCNT & SBM & $0.005-0.01$ mass $\%$ \\
\hline$[166]$ & DI & $\mathrm{GNSs} / \mathrm{Al}_{2} \mathrm{O}_{3}$ & SBM & 0.1 vol $\%$ \\
\hline$[68]$ & DW & GO & MHM & $0-0.05$ mass $\%$ \\
\hline
\end{tabular}


Table 2 (continued)

\begin{tabular}{|c|c|c|c|c|}
\hline References & Base fluid & Material & Synthesis method & Loading \\
\hline$[167]$ & $\mathrm{DI}+\mathrm{SUR}$ & GNPs/Al ${ }_{2} \mathrm{O}_{3}$ & SBM & $0.25-1.25$ vol $\%$ \\
\hline [168] & DW + SURs & GI, MWCNT & SBM & 1 mass $\%$ \\
\hline [169] & DI & GO & SBM & 0.03 mass $\%$ \\
\hline$[170]$ & $\mathrm{DW}+\mathrm{SUR}$ & GI & SBM & $0.02-0.08$ mass $\%$ \\
\hline$[171]$ & DW & GNPs & SBM & $0.025-0.1$ mass $\%$ \\
\hline$[172]$ & $\mathrm{DW}+\mathrm{SUR}$ & Carboxyl GR & SBM & $0.02-0.04$ vol\% \\
\hline$[173]$ & $\mathrm{DW}+\mathrm{SUR}$ & $\mathrm{GI}+\mathrm{MWCNT}$ & SBM & $0.25-2.0$ vol $\%$ \\
\hline$[174]$ & DW & $\mathrm{rGO}-\mathrm{Fe}_{3} \mathrm{O}_{4}$ & SHMs & 0.5 mass $\%$ \\
\hline$[175]$ & DW & rGO & SBM & 0.02 mass $\%$ \\
\hline [69] & DI & GO & MHMs & $0.01-0.1$ mass $\%$ \\
\hline$[176]$ & DI & Functionalized GNPs & SBM & 0.05 vol $\%$ \\
\hline$[177]$ & DW and EG & $\mathrm{GO} / \mathrm{Co}_{3} \mathrm{O}_{4}$ & MHMs & $0.05-0.2$ vol $\%$ \\
\hline [178] & Ethanol & GNSs & Exfoliation & $0.02-0.1 \mathrm{vol} \%$ \\
\hline$[179,180]$ & $\mathrm{DW}$ and $\mathrm{EG}+\mathrm{SUR}$ & GNPs & SBM & $0.001-0.45$ vol $\%$ \\
\hline$[181]$ & Oil & GNSs & SBM & $0.025-0.1$ mass $\%$ \\
\hline$[182]$ & DI & GNPs & SBM & $1.2-16.7$ vol $\%$ \\
\hline [183] & DI & rGO & MHM & $0.00125-0.01$ mass $\%$ \\
\hline$[184]$ & DW & GO & SBM & $0.025-0.1$ vol\% \\
\hline$[185]$ & $\mathrm{DW}+\mathrm{SUR}$ & GNPs, MWCNT & SBM & $0-0.3$ vol $\%$ \\
\hline$[186]$ & $\mathrm{DW}$ and $\mathrm{EG}+\mathrm{SUR}$ & GNPs & SBM & $0.1-0.5 \mathrm{vol} \%$ \\
\hline$[187]$ & DI & GR & SBM & 1 mass $\%$ \\
\hline$[188]$ & DW and propylene glycol & Functionalized GO & SBM & $0.25-1.0$ mass $\%$ \\
\hline [189] & DW & GONs & SBM & $0.05-0.2 \mathrm{vol} \%$ \\
\hline [190] & DI & $\mathrm{SnO}_{2} / \mathrm{rGO}$ & SBM & $0.02-0.1$ mass $\%$ \\
\hline [191] & DI & GO & MHM & $0.25-1.5 \mathrm{~g} \mathrm{~L}^{-1}$ \\
\hline [192] & EG & GO & МHM & $0.1-5$ vol $\%$ \\
\hline [193] & DW & Phenyl-sulfonic-functionalized GR & SBM & $0.02-1$ vol $\%$ \\
\hline [194] & DI & GO & МHM & $0.005-0.01$ mass $\%$ \\
\hline [195] & EG & GO & MHM & $0.01-0.05$ mass $\%$ \\
\hline [196] & DW & GNSs & SBM & $0.003-0.006$ mass $\%$ \\
\hline$[197]$ & DI & GNPs & SBM & $0.025-0.1$ mass $\%$ \\
\hline [198] & DW & GNPs & SBM & 1 mass $\%$ \\
\hline [199] & $\mathrm{DW}+\mathrm{SUR}$ & GNPs & SBM & $0.05-0.15 \mathrm{vol} \%$ \\
\hline [200] & DW & GNSs & SBM & $0.001-0.01$ mass $\%$ \\
\hline
\end{tabular}

GR graphene, GI graphite, NP nanoparticle, SUR surfactant

Fig. 12 Two-step preparation process

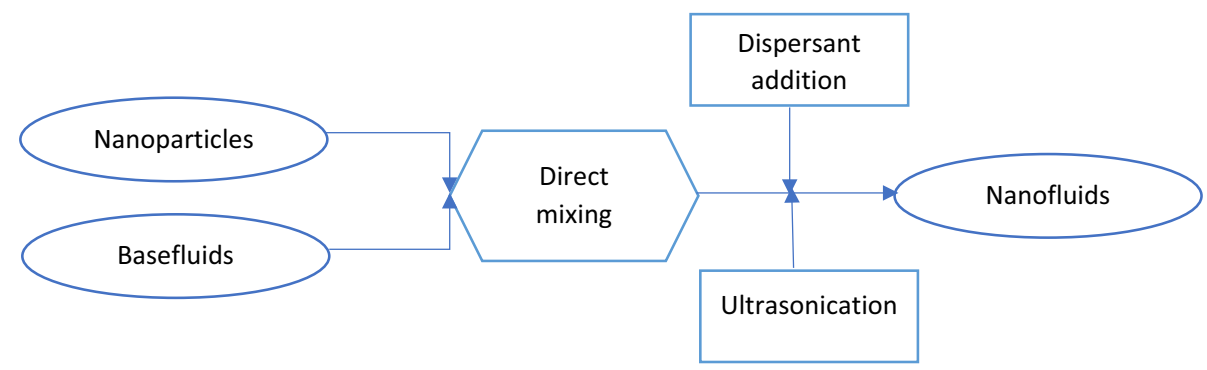


and hydroxyl functional groups were introduced on the surface of graphene under acidic and ultrasonication treatment. Then, the functionalized graphene was utilized to decorate the $\mathrm{CuO}$ nanoparticles with the help of $\mathrm{CuCl}_{2}$ and $\mathrm{NaBH}_{4}$ and $\mathrm{NaOH}$. Baby and Ramaprabhu [98] and Kole and Dey [105] utilized dried GO to produce hydrogen exfoliated graphene in hydrogen at $200{ }^{\circ} \mathrm{C}$. Its functionalization was made by treating as synthesized hydrogen exfoliated graphene with acid and ultrasonication.

Wang et al. [203] produced very steady GNFs by dispersing GO powder into the DW by using ultrasonication and adding hydrazine hydrate into the mixture. The solid product was washed with ethanol and DW and then dried at $60{ }^{\circ} \mathrm{C}$ in a vacuum oven for $24 \mathrm{~h}$ to remove the remaining solvent. Park et al. [204] and Ghozatloo et al. [104] produced GNSs by using CVD to develop the GNSs on copper foil by catalytic decomposition in a quartz tube heater system. With the reflux system and potassium persulfate, functionalization of graphene took part, and after that, it was mixed with DI. Then, it was homogenized in the ultrasonic bath for $1 \mathrm{~h}$ to producing the GNF.

With other BFs, Agarwal et al. [132] prepared GNPs-kerosene nanofluids with surfactant by the two-step process. Luo et al. [76] used this technique to produce GO nanofluids of oil and water, while Su et al. [160] worked with n-butanol alcohol aqueous solution. Wang et al. [156] and Qing et al. [157] produced GNFs of oil. Cabaleiro et al. [158] and Selvam et al. [153, 162] used EG for nanofluid production in their studies.

\section{Stability of nanofluids}

Nanofluids are able to lose their potentiality to transfer heat for the reason that nanoparticles have a tendency of coagulation involving electrical double-layer action, steric action, and van der Waals forces. Balancing the competing interactions supports nanoparticle dispersion and prevents aggregation and clustering that were investigated as factors increasing TC of nanofluids. As a result, investigation on a stable and homogeneous nanofluid is an unavoidable and great challenge of nanofluid preparations. This section reviews the stability enhancement procedures and stability development methods. A complete list of research work on the stability of various GNFs is available in Table 3.

\section{Stability enhancement procedures}

Various methods are used for obtaining stable nanofluids, including physical methods (i.e., mechanical agitation, stirring, and ultrasonic vibration) or chemical treatment (i.e., addition of surfactant, $\mathrm{pH}$ control). Nanofluid stability is directly related to its electrokinetic properties.
Consequently, their $\mathrm{pH}$ control can increase the stability due to strong repulsive forces. The $\mathrm{pH}$ can control the van der Waals and electrostatic forces. As for instance, acid treatment can improve the dispersible ability of graphene in $\mathrm{BF}$ and enhance the TC of GNF [207]. Yarmand et al. [147, 161] studied the functionalized GNPs-based nanofluids from a simple acid treatment reaction procedure, and the nanofluids were stable for a long time without sedimentation. Vallejo et al. [208] investigated the effect of various $\mathrm{pH}$ values of GNP nanofluids in propylene glycol-water mixture and observed that the absolute values of zeta potential were higher than $30 \mathrm{mV}$ for samples with $\mathrm{pH}$ values above 6 . With the same method, Askari et al. [209] showed that the suitable $\mathrm{pH}$ value for $\mathrm{Fe}_{3} \mathrm{O}_{4}$ /graphene nanofluids of water is 8 and 10 .

Surfactants utilized in nanofluids are called dispersants. Utilizing surfactants in the two-phase systems is an economical and easy way to make the nanofluids in steady state. Surfactants are able to decrease the surface tension of BFs and rise the particle immersion. Surfactants consist of a hydrophobic tail portion, e.g., a hydrophilic polar head group and a long-chain hydrocarbon, which could help to modify hydrophobic materials to enable the dispersion in aqueous solution. In researches, for various kinds of nanofluids, some types of surfactants were utilized. Some important surfactants with GNFs are: sodium carboxymethyl celluloses (NaCMC) [131], oleylamine [132], sodium dodecyl sulfate (SDS), sodium dodecyl benzene sulfonate (SDBS) [135], Tween 80, Acumer Terpolymer [54], sodium deoxycholate (NaDC) [162], Triton X100 [54, 80, 139], gum arabic (GA), cetyltrimethylammonium bromide (CTAB) [54, 135]. Nevertheless, using surfactants also affects the thermophysical characteristics of the nanofluids in many ways $[54,135$, 210]. It should be noted that this technique cannot be useful for nanofluids acting at high temperature as a result of damage of bonding between the nanoparticle and surfactant. Surfactants may produce foams while heating. Furthermore, surfactants can extend the thermal resistance of the nanofluids because the surfactants attach to the nanoparticle surfaces. These restrictions are able to limit the enhancement of the effective TC.

The surface modification technique is a surfactant-free technique that can deliver long-term nanofluid stability. A lot of researchers utilized such modification techniques. Myekhlai et al. [144] presented work on the production of graphene and silver nanoparticles composite by adding silver to the surface of graphene. It was noted that the combination of silver and graphene in the composite material considerably improved the thermal conductivity of BF and the specific surface area is enhanced. Yarmand et al. [147, 161] increased the stability of nanofluids by introducing the hydroxyl and carboxyl function groups toward the GNP surface. With the same purpose, Mehrali et al. [80] prepared NDG by a hydrothermal process with GO as a raw material 
Table 3 Summary of different stability of nanofluid research

\begin{tabular}{|c|c|c|c|}
\hline References & Stability test method & Duration & Surfactant \\
\hline [93] & $\mathrm{TC}$ & $\sim 7$ days & N/A \\
\hline$[101]$ & $\mathrm{ZPT}$ & N/A & Modifying $\mathrm{pH}$ \\
\hline$[103]$ & SPC & $>6$ months & N/A \\
\hline [205] & $\mathrm{SPC}+\mathrm{UV}-\mathrm{Vis}$ & N/A & Polymers P19 and P20 \\
\hline [206] & $\mathrm{ZPT}$ & N/A & Changing $\mathrm{pH}$ \\
\hline [104] & $\mathrm{SPC}+\mathrm{TC}$ & $\sim 7$ days & N/A \\
\hline$[105]$ & $\mathrm{TC}$ & $\sim 150$ days (5 months) & N/A \\
\hline$[117]$ & $\mathrm{SPC}+\mathrm{UV}-\mathrm{Vis}$ & $\sim 7$ days & N/A \\
\hline [118] & SPC, UV-Vis, ZPT & $\sim 60$ days & N/A \\
\hline [115] & SPC & N/A & N/A \\
\hline [114] & SPC, UV-Vis, ZPT & $\sim 180$ days (6 months) & Triton X-100 \\
\hline [113] & $\mathrm{SPC}$ & N/A & N/A \\
\hline$[112]$ & $\mathrm{SPC}$ & $24 \mathrm{~h}$ & N/A \\
\hline$[3]$ & SPC, UV-Vis, ZPT & $600 \mathrm{~h}$ & N/A \\
\hline$[107]$ & $\mathrm{UV}-\mathrm{Vis}$ & 1 week & PVA \\
\hline$[123]$ & SPC & 7 days & N/A \\
\hline$[122]$ & $\mathrm{ZPT}+\mathrm{SPC}$ & N/A & Modifying $\mathrm{pH}$ and tannic acid \\
\hline$[121]$ & $\mathrm{SPC}$ & 2 months & Modifying $\mathrm{pH}$ \\
\hline$[124]$ & SPC & 4 days & SDBS \\
\hline [129] & $\mathrm{SPC}+\mathrm{UV}-\mathrm{Vis}$ & $256 \mathrm{~h}$ & N/A \\
\hline$[131]$ & ZPT, PSD, SPC & $\sim 1$ month & Sodium carboxymethyl celluloses \\
\hline$[132]$ & $\mathrm{DLS}+\mathrm{TC}$ & $\begin{array}{l}>2 \text { months }(0.005 \%) \text {, few days } \\
(>0.005 \%)\end{array}$ & Oleylamine \\
\hline$[133]$ & $\mathrm{ZPT}$ & N/A & N/A \\
\hline$[135]$ & ZPT, UV-Vis & $\sim 60$ days & $\begin{array}{l}\text { Gum arabic, cetyltrimethylammonium } \\
\text { bromide, sodium dodecyl sulfate, sodium } \\
\text { dodecyl benzene sulfonate }\end{array}$ \\
\hline$[136]$ & $\mathrm{ZPT}$ & N/A & N/A \\
\hline [139] & UV-Vis & $\sim 200$ days & Triton X-100 \\
\hline$[76]$ & SPC & $\sim 30$ days & N/A \\
\hline$[142]$ & ZPT & $\sim 45$ days & N/A \\
\hline$[143]$ & $\mathrm{ZPT}$ & N/A & N/A \\
\hline [77] & ZPT, DLS & N/A & N/A \\
\hline [78] & $\mathrm{ZPT}$ & N/A & N/A \\
\hline$[65]$ & UV-Vis & $\sim 1$ week & N/A \\
\hline$[54]$ & $\mathrm{ZPT}$ & N/A & $\begin{array}{l}\text { Gum arabic, Tween } 80 \text {, CTAB, Triton } \\
\text { X100, Acumer Terpolymer }\end{array}$ \\
\hline$[80]$ & $\mathrm{UV}-\mathrm{Vis}$ & $\sim 10$ days & Triton X-100 \\
\hline$[147]$ & $\mathrm{UV}-\mathrm{Vis}$ & $\sim 10$ days & N/A \\
\hline$[74]$ & $\mathrm{ZPT}$ & N/A & N/A \\
\hline [149] & SEM & $12 \mathrm{~h}$ & N/A \\
\hline$[156]$ & SPC & $\sim 30$ days & N/A \\
\hline$[157]$ & ZPT, UV-Vis & $\sim 2$ weeks & N/A \\
\hline$[158]$ & $\mathrm{ZPT}$ & N/A & N/A \\
\hline$[64]$ & SPC, UV-Vis & $\sim 2$ weeks & N/A \\
\hline [159] & UV-Vis & $\sim 60$ days & N/A \\
\hline$[161]$ & $\mathrm{UV}-\mathrm{Vis}$ & $\sim 528 \mathrm{~h}$ & N/A \\
\hline$[162]$ & UV-Vis & $\sim 15$ days & Sodium deoxycholate \\
\hline$[66]$ & $\mathrm{UV}-\mathrm{Vis}$ & $>5$ months & N/A \\
\hline$[67]$ & UV-Vis, ZPT & N/A & N/A \\
\hline
\end{tabular}


Table 3 (continued)

\begin{tabular}{llll}
\hline References & Stability test method & Duration & Surfactant \\
\hline$[165]$ & TC & $\sim 4$ days & N/A \\
{$[68]$} & SPC & $>15$ days & N/A \\
{$[168]$} & ZPT & N/A & $\begin{array}{c}\text { Sodium dodecyl sulfate, sodium dodecyl } \\
\text { benzene sulfonate, dodecyl betaine }\end{array}$ \\
{$[169]$} & ZPT, PSD & $\sim 30$ days & N/A \\
{$[174]$} & UV-Vis & $\sim 60$ days & N/A \\
{$[175]$} & ZPT, SPC & $\sim 2$ months & N/A \\
{$[176]$} & Sedimentation balance method & $\sim 34$ days & N/A \\
{$[179,180]$} & UV-Vis, ZPT & $\sim 15$ days & Sodium deoxycholate \\
{$[183]$} & UV-Vis & $\sim 10$ days & N/A \\
{$[184,189]$} & SPC, ZPT & $\sim 3$ months & N/A \\
{$[190]$} & ZPT & $\sim 60$ days & N/A \\
{$[196]$} & ZPT & N/A & N/A \\
\hline
\end{tabular}

in an ammonia solution. Grinding can be utilized to enhance significantly the dispersibility property in BF water [207].

After the nanofluid preparation, an agglomeration can occur over time, which causes rapid sedimentation of the particles as a result of enhancement of downward body force. The physical techniques used to promote stability of nanofluids are stirring, mechanical agitation, and ultrasonic vibration. Several researchers have used mechanical stirring techniques, where the working BF was DW [56, 211]. Many authors have studied the use of ultrasonic vibration to disperse and suspend in many BFs. For instance, Ahmadi et al. [212] studied the importance of sonication time on the stability of nanofluids.

The stability of nanofluids has been a main and challenging problem so far. This limits the utilization of nanofluids in heat transfer applications. Thus, further investigation is required to obtain optimum methods to enhance the thermal and chemical stability of GNFs on the optimum basis, surface modification techniques of nanoparticles, and the use of various surfactants.

\section{Stability mechanisms}

Stabilization of nanofluids is the most urgent concern. It means the nanoparticles do not agglomerate at a significant speed. The reason for the agglomeration of the nanoparticle is that nanoparticles in nanofluid are able to attach together as a result of the attractive force against the repulsive force. Respectively, they are van der Waals and electrical double layer, which exist between nanoparticles. Also, they come close to others by reason of the random Brownian motion [213]. When attraction prevails over repulsion, two nanoparticles will collide, and nanoparticles tend to agglomerate in clusters. In contrast, if nanoparticles have stronger repulsion than attraction, then nanofluids will exist in steady state. Accordingly, the enhancement of repulsive force can ensure

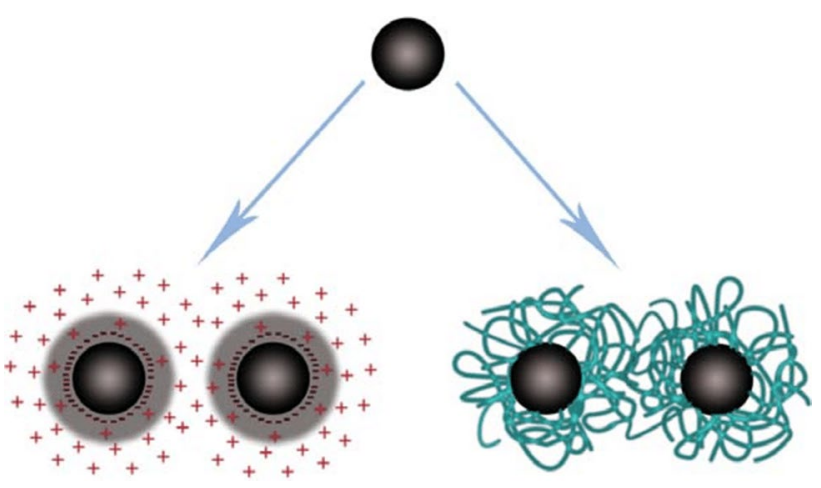

Fig. 13 Electrostatically and sterically stable nanoparticles [215]

to keep nanofluid in steady state and prevent the nanoparticle agglomeration. As specified by the repulsion kinds, the fundamental mechanisms are divided into two kinds: steric stabilization and electrostatic stabilization [214], shown in Fig. 13.

For steric stabilization, macromolecules (polymers, surfactants) are involved in the colloidal system. They will be attached or grafted to the surfaces of the particles, producing an additional steric repulsive barrier to prevent the particle from coming close to each other [216, 217]. For instance, Askari et al. [66] grafted oleic acid on the surface of $\mathrm{Fe}_{3} \mathrm{O}_{4}$-decorated graphene nanoparticles by chemisorption and the nanofluids have good stability. GNPs nanofluids are very stable on account of the protective role of oleylamine, as it prevents the growth and agglomeration of nanoparticles by the steric effect. This effect of surfactant is determined by the concentration of the surfactant. Agarwal et al. [132] found that for maximum stabilization of nanofluid the oleylamine to GNP mass ratio is 0.6. 
For electrostatic stabilization, the existence of surface charge or Coulomb repulsion is a major source of stabilization. Electrostatic stabilization is developed through the following mechanisms: preferential adsorption of ions, the isomorphic substitution of ions, dissociation or physical adsorption of surface-charged species, accumulation or depletion of electrons at the surface [218, 219]. Electrostatic interactions are a $\mathrm{pH}$-sensitive way [67]. Therefore, the electrostatic stabilization is limited to use.

\section{Stability evaluation methods for nanofluids}

Stabilization of nanofluid can be estimated through measurement of the exact amount of the settled and suspended nanoparticles in BF over time. There are six different methods to study the stabilization of nanofluids as follows: UV-Vis spectrophotometry, ZPT, SPC, SEM and TEM, sedimentation balance method, $3 \omega$ method, centrifugal dispersion analysis, and TC. A summary of some studies on the stabilization of nanofluid is given in Table 3 .

In nanofluid, zeta $(\zeta)$-potential is the difference of potential between the immobile sheet of BF grafted to the nanoparticle and BF. The electrical potential is considered as $\zeta$-potential that is associated with the repulsive force between neighboring, analogously charged nanoparticles in the suspension system. Therefore, nanofluids having low $\zeta$-potentials will gradually coagulate, when nanofluids with high $\zeta$-potentials (positive or negative) are known as electrically stabilized. Nanofluids are believed to have good stabilization with $\zeta$-potential between 40 and $60 \mathrm{mV}$ (see Fig. 14). Nanofluids with $\zeta$-potentials higher than $60 \mathrm{mV}$ are known as having excellent stabilization [220]. Many researchers $[131,133,135,136]$ utilized ZPT to study the stability of

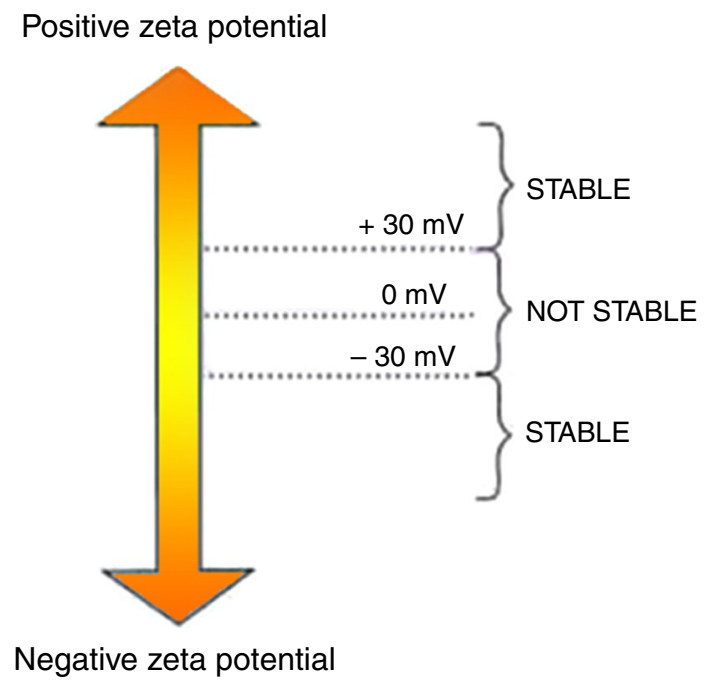

Fig. 14 Scheme for $\zeta$-potential of stable and unstable dispersions [221] nanofluids because of the simplicity of the technique. Vakili et al. [142] utilized this method for GNP nanofluids, and Tahani et al. [143] also utilized it for GO nanoplatelets.

Sedimentation method is the most elementary and simplest technique to evaluate the stability of nanofluids [222]. The sediment amount is an expression of the stabilization of the characterized nanofluids under an external force field to start the sedimentation of nanoparticles. When the concentration or particle size of the supernatant particles remains constant over time, the nanofluids are generally considered to be stable. Wang et al. [156] used the principle of this technique in their own experimental setup for measuring the stabilization of the GNFs.

Spectral absorbance analysis via UV-Vis spectrophotometer is another efficient way for evaluation of the stability of the nanofluids. Generally, there is a linear relationship between the concentration of nanoparticles in fluid and the absorbance intensity. The advantage of this method comparing to other methods is that UV-Vis spectroscopy can give a concentration of nanofluids. Many researchers analyzed the stability of nanofluids by measuring the UV-Vis absorption after different sediment time (see Fig. 15) [65, 135, 139, $159,161,162]$.

However, many methods were utilized for improving stability of GNFs. In the literature, the methods can only make a stable nanofluid for only some days or months and nanofluids with long-term stability are not available. So, more studies are required for suppressing the formation of nanoparticle cluster and changing the surface properties of suspended nanoparticles to obtain homogeneous and stable nanofluids.

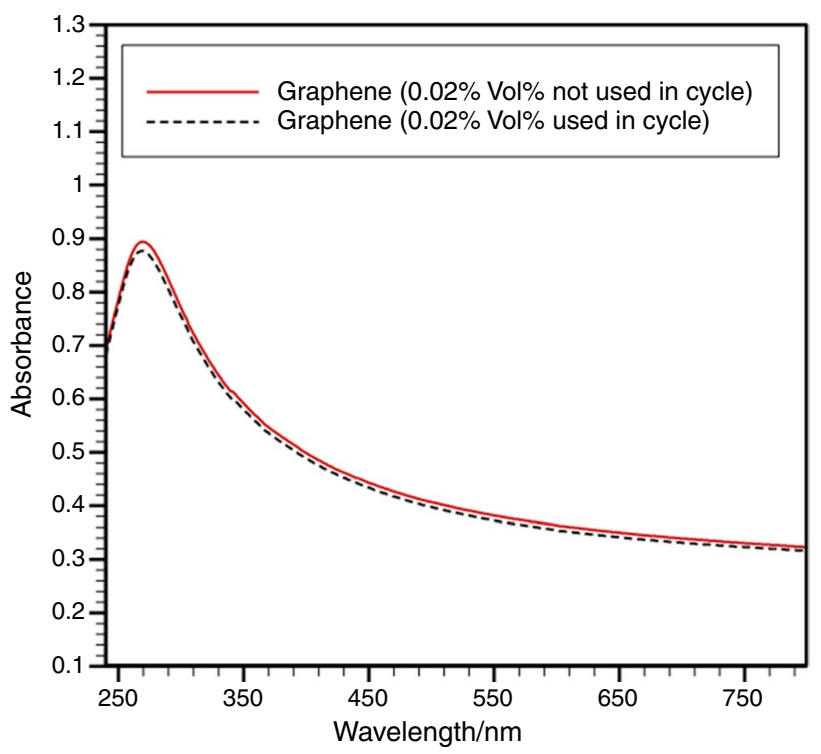

Fig. 15 UV-Vis spectra of GNF before and after using the nanofluid in the testing cycle duration of 1 week [114] 
Table 4 Specifications of GNP, GO, and their nanofluids (BF/water)

\begin{tabular}{lll}
\hline Property & GNP [3] & GO [115] \\
\hline Particle & GNPs & GO \\
Color & Black granules/powder & Brown granules/powder \\
Peak in UV-Vis spectrophotometer & 265 to $270 \mathrm{~nm}$ & $227 \mathrm{~nm}$ \\
Thickness & $2 \mathrm{~nm}$ & $<2 \mathrm{~nm}$ \\
Stability of nanofluid & $600 \mathrm{~h}$ & 1 week \\
Zeta potential $(0.1 \mathrm{mass} \%)$ & $-45.7 \mathrm{mV}$ & $-43.1 \mathrm{mV}[223]$ \\
Viscosity $\left(0.1 \mathrm{mass} \%\right.$, shear rate $\left.1001 \mathrm{~s}^{-1}\right)$ & $1.3 \mathrm{mPa} \mathrm{s}\left(20{ }^{\circ} \mathrm{C}\right), 0.9 \mathrm{mPa} \mathrm{s}\left(40{ }^{\circ} \mathrm{C}\right)$ & $1.4 \mathrm{mPa} \mathrm{s}\left(25^{\circ} \mathrm{C}\right), 0.8 \mathrm{mPa} \mathrm{s}\left(40{ }^{\circ} \mathrm{C}\right)[77]$ \\
TC enhancement & $11.94 \%(0.025 \mathrm{mass} \%)$ & $11.67 \%, 14.75 \%(0.05 \mathrm{mass} \%)$ \\
GNP: at $35^{\circ} \mathrm{C} ; \mathrm{GO}:$ at $30{ }^{\circ} \mathrm{C}$ and $40{ }^{\circ} \mathrm{C}$ & $27.64 \%(0.1 \mathrm{mass} \%)$ & $15.00 \%, 24.59 \%(0.1 \mathrm{mass} \%)$ \\
EC $\left(0.1 \mathrm{mass} \%, 25^{\circ} \mathrm{C}\right)$ & $1.2 \times 10^{-3} \mathrm{~S} \mathrm{~m}^{-1}$ & $5.1 \times 10^{-3} \mathrm{~S} \mathrm{~m} \mathrm{~m}^{-1}[118]$ \\
\hline
\end{tabular}

\section{GO and GNFs}

GO and graphene/water nanofluids have long-term stability. Almost, no sedimentation of GO and graphene was observed in water after one week. Table 4 shows that these nanofluids have zeta potential below $-30 \mathrm{mV}$; thus, it is confirmed that they have good stability. This also shows that between GNPs and GOs the electrostatic repulsive force is strong enough to get over the attractive force between nanoparticles. In addition, greater electrostatic force can make more free particles state easily because the distance between particles increases. Thus, the hydrogen bonding range between particles is exceeded, and further, the chance of particle coagulation and settling is decreased.

A rise in viscosity has to be examined. The viscosity of nanofluid affects fluid dynamics and results in a pressure drop that is significant from the perspective of the fluid application. At low temperatures, GNP nanofluids have more benefits because of lower viscosity compared to GO nanofluids, see Fig. 16. At higher temperatures, the viscosity of the nanofluid is lower because of the weakening of the

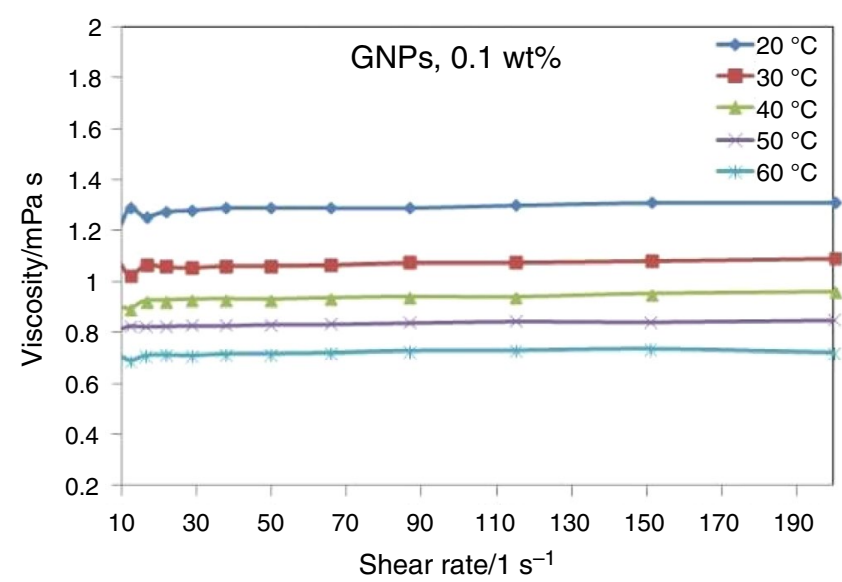

intermolecular and interparticle adhesion forces. The viscosity of DW decreased exponentially as a function of shear rate which shows non-Newtonian shear thinning behavior (pseudoplastic). Like BF, the samples of GNP, GONFs exhibit this property.

The most interesting property in nanofluids is its TC, which shows the ability of a nanofluid to conduct heat. The TC enhancement of nanofluids depends highly on features of dispersed nanoparticles, such as the conductivity of the nanoparticles. From Tables 4 and 5, it can be seen that the TC of the GNPs is higher than that of the GO. For composites, there are some standard TC models like the Maxwell model, Hamilton-Crosser. However, these models present weakness in predicting the thermal conductivities of nanofluids, so various new mechanisms have been proposed. Several researchers indicated the Brownian motion of nanoparticles as a main element for the observed enhancement of the TC. However, the nanoparticle aggregation and the existence of a nanolayer at the solid-liquid interface can make a major contribution to the mechanisms of TC improvement of nanofluids. The BF molecules near the nanoparticle surfaces form

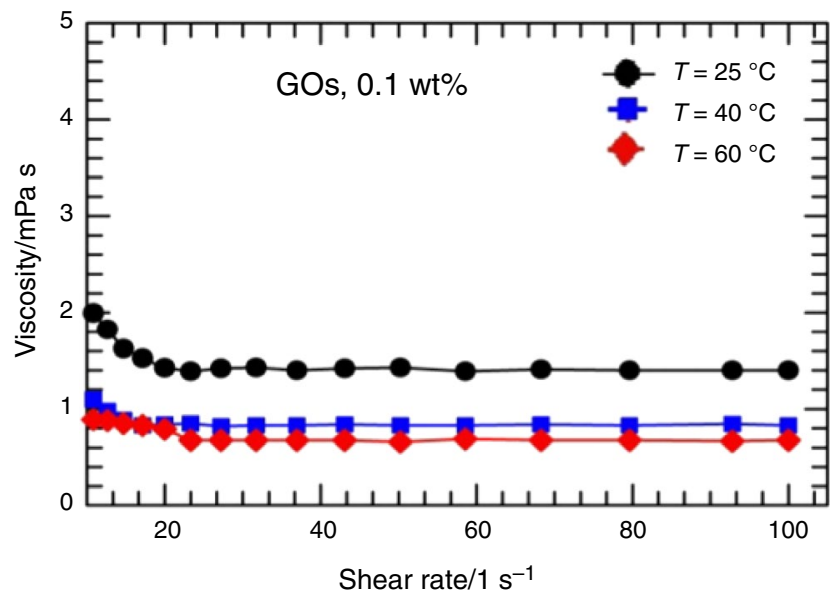

Fig. 16 Plots of viscosity versus the shear rate at various concentrations and temperatures for GNP and GO nanofluids [3, 77] 
Table 5 Dimensions, carbon content, TC of graphene, GO nanoplatelets [224]

\begin{tabular}{llllll}
\hline Sample & Thickness/nm & $\begin{array}{l}\text { Lateral dimen- } \\
\text { sions/ } \mu \mathrm{m}\end{array}$ & $\begin{array}{l}\text { Carbon } \\
\text { content/\% }\end{array}$ & $\begin{array}{l}\text { Interlayer spac- } \\
\text { ing/nm }\end{array}$ & TC/W m ${ }^{-1} \mathrm{~K}^{-1}$ \\
\hline GNPs & $\sim 10$ to 15 & $\sim 15$ to 20 & $\sim 99$ & 0.3372 & $2275 \pm 338$ \\
GNPs & $\sim 10$ to 15 & $\sim 15$ to 20 & $\sim 99$ & 0.3376 & $2180 \pm 314$ \\
$\begin{array}{l}\text { Oxygen-interca- } \\
\quad \text { lated graphene }\end{array}$ & $\sim 1$ to 2 & $\sim 5$ & $\sim 93$ & 0.3540 & $776 \pm 96$ \\
GO & $\leq 1$ & $\sim 1$ & $\sim 46$ & 0.3827 & $18 \pm 2$ \\
\hline
\end{tabular}

layered structured and act as a solid. Using a low concentration of GNP nanofluids can obtain acceptable TC enhancement for applications of solar collectors, thermal exchanger systems.

The EC has not been studied widely as TC, although it is an important property. The EC of a nanofluid can increase or decrease depending on the BF, size, loading, and charge of the nanoparticles. Through the results, it could be seen that the enhancement of EC of GONFs was better than of GNP nanofluids. The reason can be that the surface charge of nanoparticles has a big role in enhancing EC of the nanofluids, and GO nanoparticles have higher surface charges originating from its functional groups.

\section{Applications of GNF}

Different types of GNFs have been used for a large range of engineering application, such as heat pipes, sensors, micro-mini-channels, clean energy devices, heat sinks, composite materials, automobiles, medicine, cosmetic, airconditioning, refrigeration, solar energy device, lubricants, and coolants as shown in Fig. 17.

Due to the rapid development of modern technology, a higher density of chips, recent electronic devices with more compact dimensions generate a tremendous amount of heat. This reduces the normal efficiency of the advanced electronic devices and reduces expected life and reliability. Thus, the reliable thermal management system is essential for good working of electronic devices. Generally, heat removal can be improved with two approaches: finding an optimum geometry of cooling devices and increasing the heat transfer capacity. Ali and Arshad [226, 227] used GNF with pin-fin heat sinks. This contributed a striking advancement in active cooling technology with GNPs/DW nanofluid. The integral fin heat sink with GNPs nanofluid is appropriate for electronic devices that dissipate the maximum heat flux around $50 \mathrm{~kW} \mathrm{~m}^{-2}$.

The heat pipe, a two-phase thermal transfer device, is explored with different coolant mediums as an active and passive cooling technology. Different graphene-based nanomaterials such as GO, GNPs in a miniature loop heat pipe, oscillating heat pipe, wick, and grooved heat pipe have been studied and have obtained remarkable improvement in thermal transfer efficiency [133, 139, 151, 160, 196]. It is believed that the functionalization of GNPs may present the various impacts in heat efficiency of the heat pipe. Thus, it is recommended to compare the thermophysical and heat transfer efficiency of functionalized and nonfunctionalized graphene-based nanomaterials by changing base liquids.

Heat management of automotive engines much impacts the efficiency of vehicles indirectly and directly as it influences motor efficiency, fuel utilization, human comfort, emissions, component life, maintenance, and vehicles quality. For the effective cooling of motors utilizing GNF has been investigated by different researchers. Amiri et al. [228] used crumpled NDG with DW-EG mixture, and Selvam et al. [180, 186] utilized GNPs dispersed in water-EG as a coolant through an automobile radiator. It can be released that with higher loading of GNPs, a higher heat transfer coefficient is obtained. The authors suggest more investigations for various $\mathrm{BF}$, loading, inlet temperature across the car radiator.

The use of mini-channel with GNFs has been reported for thermal system applications by some researchers. Ahammed et al. [166] performed an experimental study for entropy generation analysis in a multiport mini-channel heat exchanger coupled with a thermoelectric cooler. It can be observed that the thermal efficiency of GNFs is better than $\mathrm{Al}_{2} \mathrm{O}_{3}$ nanofluid and hybrid nanofluid containing $\mathrm{Al}_{2} \mathrm{O}_{3}$ and graphene.

The heat exchanger is utilized broadly in industry and particularly in process plants, for example power plants, cooling towers, refineries, etc. The key challenge is the powerful heating and cooling of processing liquids inside the heat exchangers. To improve the heat exchange rate the conventional technique is to increase the surface area; however, here the cost comes to the main parameter. Some researches accessible on effective cooling of heat exchanger with GNFs on flow arrangement [189, 229], flow regime [128, 184], and construction [153, 164]. From the studies, at a fixed $\mathrm{Re}$ number, the rise of loading graphene to water enhances the convective heat transfer coefficient. Furthermore, higher Re number and concentration of graphene cause the increment in friction factor, which results in increasing the pressure drop and pumping power. 


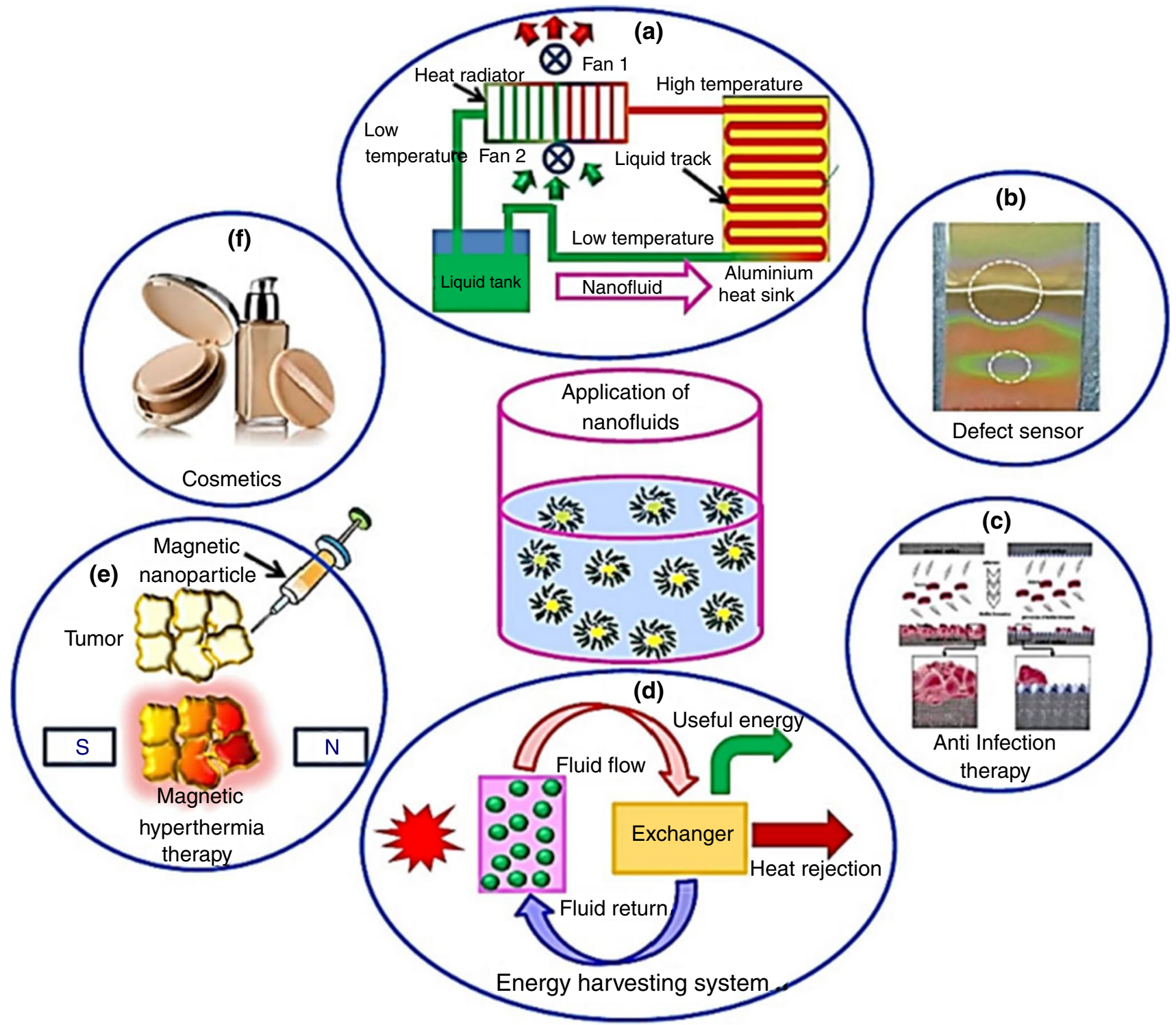

Fig. 17 Several utilizations of GNFs [225]

Some studies have been presented on boiling heat transfer under various regimes and boiling parameters with GNFs [230]. Pool boiling heat transfer is still investigated to decrease or increase the rate of heat transfer. Several researchers [92, 101, 102, 108, 231] used graphene with DW reporting the improvement in critical heat flux and boiling heat transfer coefficient by modifying heater size, shape, material, diameter and orientation, the heat of channel surface condition, the degree of surface wetting, etc.

Researchers [64, 136, 142, 211, 232] have investigated GNFs in direct absorption solar collector and flat plate solar collector, focusing on enhancement of the absorption of solar irradiation. Wang et al. [156] used graphene/ oil-based nanofluid with low graphene concentration to examine the dispersion stability, TC, and kinetic viscosity by changing mass fraction. The TC of nanofluids was enhanced remarkably, and the kinetic viscosity of nanofluids reduced compared with that of pure oil. It is observed that GNFs improved remarkably solar-to-thermal energy conversion and heat transfer efficiency as compared to the BF to enhance the system thermal efficiency. The authors recommend to further investigate graphene-based nanoparticles with metallic and metallic oxides nanoparticles by changing the concentration, inlet temperature, flow rate, and pumping power. 
Fig. 18 Future challenges of GNFs

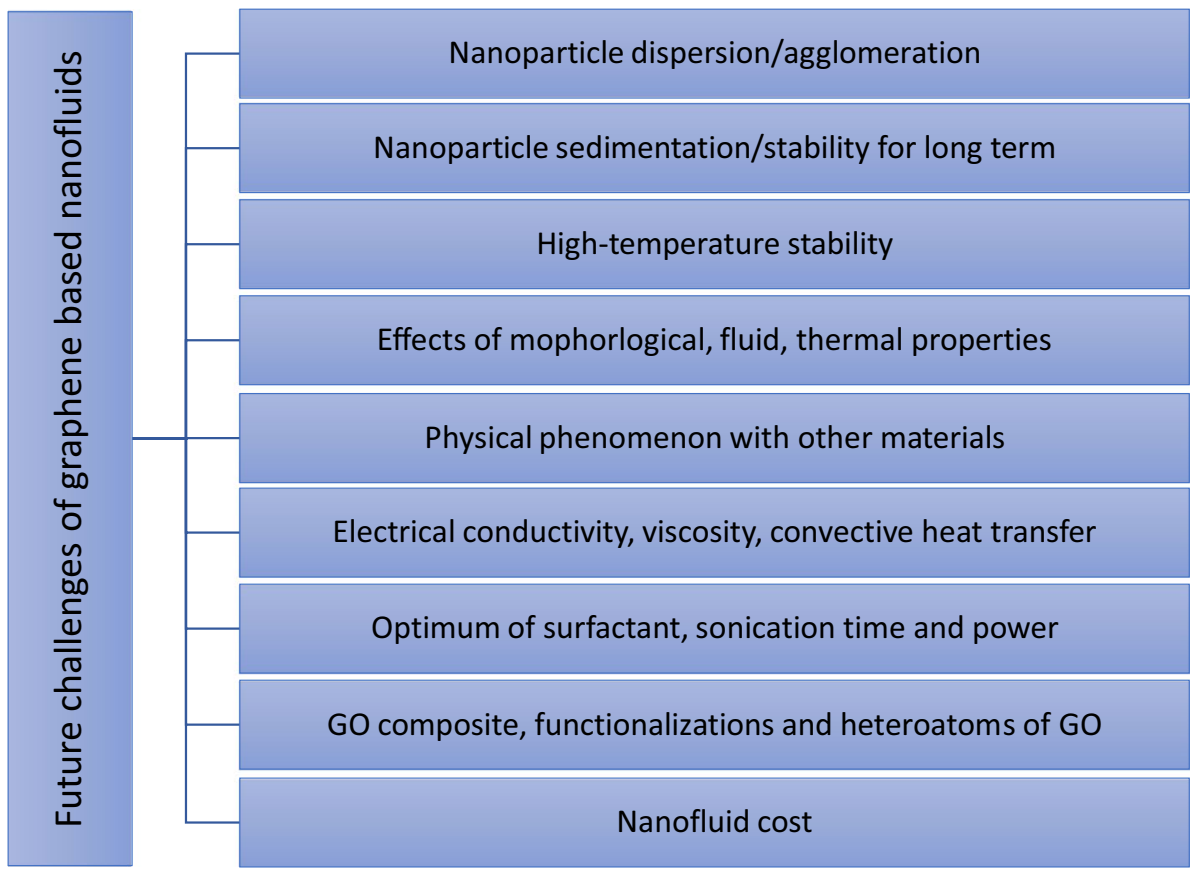

\section{Conclusions and outlook}

In the review article, most investigations performed on the preparation and stability of different GNFs have been covered. It has been found that the two-step preparation method has been accepted by a majority of the researchers because of its simplicity and economic benefits. Moreover, the steps and mechanisms in the stabilization process of these nanofluids have been discussed. Figure 18 summarizes the future challenges for GNFs.

The shape of graphene nanoparticles is very important for their properties. There is a need to investigate further the effect of morphological, fluid and thermal properties, and use of different BFs, which helps to increase the thermal and flow performance and improve the production of nanofluids. The long-term stability of GNFs should be investigated more for many practical applications. There are very few researches on the long term of stability of these nanofluids.

Another interesting topic is decreasing the cost of GNF. The high-temperature stability has not been investigated as well. In different high-temperature thermal applications, the physical phenomenon with other materials should be studied as corrosion, friction. Additionally, the EC, viscosity, and convective heat transfer coefficient of nanofluids should be investigated widely as their TC, which are important for nanofluid research. Development of more suitable surfactants and methods, the optimum amount of surfactant for better stability of nanofluids will be an interesting topic. Another important research priorities are the investigation of sonication time and power on GNFs and finding the optimal settings [233]. More research is needed for GO composite-based nanofluids, i.e., GO can have a composite with inorganic materials. In addition, various functionalizations and heteroatoms of GO can be checked in more detail. Finally, theoretical models need to be developed further to explain the experimental data on different parameters affecting heat transfer performance; then, these parameters can be optimized for various applications.

Acknowledgements Open access funding provided by Budapest University of Technology and Economics (BME). I. M. Szilágyi thanks for a János Bolyai Research Fellowship of the Hungarian Academy of Sciences and the ÚNKP-18-4-BME-238 New National Excellence Program of the Ministry of Human Capacities, Hungary. A GINOP-2.2.115-2017-00084, an NRDI K 124212, and an NRDI TNN_16 123631 grants are acknowledged. The work performed within project VEKOP2.3.2-16-2017-00013 was supported by the European Union and the State of Hungary, co-financed by the European Regional Development Fund. The research reported in this paper was supported by the Higher Education Excellence Program of the Ministry of Human Capacities in the frame of Nanotechnology and Materials Science research area of Budapest University of Technology (BME FIKP-NAT).

Authors' contributions All authors read and approved the final manuscript.

Open Access This article is licensed under a Creative Commons Attribution 4.0 International License, which permits use, sharing, adaptation, distribution and reproduction in any medium or format, as long as you give appropriate credit to the original author(s) and the source, provide a link to the Creative Commons licence, and indicate if changes were made. The images or other third party material in this article are included in the article's Creative Commons licence, unless indicated otherwise in a credit line to the material. If material is not included in the article's Creative Commons licence and your intended use is not permitted by statutory regulation or exceeds the permitted use, you will 
need to obtain permission directly from the copyright holder. To view a copy of this licence, visit http://creativecommons.org/licenses/by/4.0/.

\section{References}

1. Choi SUS, Eastman JA. Enhancing thermal conductivity of fluids with nanoparticles. ASME Int Mech Eng Congr Expo. 1995;66:99-105.

2. Yang L, Ji W, Mao M, Huang J. Dynamic stability, sedimentation, and time-dependent heat transfer characteristics of $\mathrm{TiO}_{2}$ and CNT nanofluids. J Therm Anal Calorim. 2019. https://doi. org/10.1007/s10973-019-09103-w.

3. Mehrali M, Sadeghinezhad E, Latibari ST, Kazi SN, Mehrali M, Zubir MNBM, et al. Investigation of thermal conductivity and rheological properties of nanofluids containing graphene nanoplatelets. Nanoscale Res Lett. 2014;9:15.

4. Asadi A, Aberoumand S, Moradikazerouni A, Pourfattah F, Żyła $\mathrm{G}$, Estellé P, et al. Recent advances in preparation methods and thermophysical properties of oil-based nanofluids: A state-ofthe-art review. Powder Technol. 2019;352:209-26.

5. Suneetha S, Reddy PBA. Investigation on graphene nanofluids and its applications: A brief literature review. Res J Phar Technol. 2016;9(6):655-63.

6. Alam SN, Sharma N, Kumar L. Synthesis of Graphene Oxide (GO) by modified Hummers method and its thermal reduction to obtain reduced Graphene Oxide (rGO)*. Graphene. 2017;06:1-18.

7. Yu W, Xie H, Wang X, Wang X. Significant thermal conductivity enhancement for nanofluids containing graphene nanosheets. Phys Lett A. 2011;375:1323-8.

8. Arshad A, Jabbal M, Yan Y, Reay D. A review on graphene based nanofluids: preparation, characterization and applications. J Mol Liq. 2019;279:444-84.

9. Qiu L, Zhu N, Feng Y, Michaelides EE, Żyła G, Jing D, et al. A review of recent advances in thermophysical properties at the nanoscale: From solid state to colloids. Phys Rep. 2019;843:1-81.

10. Rowley-Neale SJ, Randviir EP, Dena ASA, Banks CE. An overview of recent applications of reduced graphene oxide as a basis of electroanalytical sensing platforms. Appl Mater Today. 2017;10:218-26.

11. Taghioskoui M. Trends in graphene research. Mater Today. 2009;12:34-7.

12. Huang X, Qi X, Boey F, Zhang H. Graphene-based composites. Chem Soc Rev. 2012;41:666-86.

13. Suk JW, Piner RD, An J, Ruoff RS. Mechanical properties of monolayer graphene oxide. ACS Nano. 2010;4:6557-64.

14. Ruhl G, Wittmann S, Koenig M, Neumaier D. The integration of graphene into microelectronic devices. Beilstein J Nanotechnol. 2017;8:1056-64.

15. Rogers JA. Making graphene for macroelectronics. Nat Nanotechnol. 2008;3:254-5.

16. Kim H, Park K-Y, Hong J, Kang K. All-graphene-battery: bridging the gap between supercapacitors and lithium ion batteries. Sci Rep. 2015;4:5278.

17. Bakandritsos A, Jakubec P, Pykal M, Otyepka M. Covalently functionalized graphene as a supercapacitor electrode material. FlatChem. 2019;13:25-33.

18. Ma W, Zhang D. Multifunctional structural supercapacitor based on graphene and magnesium phosphate cement. J Compos Mater. 2019;53:719-30.

19. Liu Y, Dong X, Chen P. Biological and chemical sensors based on graphene materials. Chem Soc Rev. 2012;41:2283-307.
20. Pan K, Fan Y, Leng T, Li J, Xin Z, Zhang J, et al. Sustainable production of highly conductive multilayer graphene ink for wireless connectivity and IoT applications. Nat Commun. 2018;9:5197.

21. Liang J, Wang Y, Huang Y, Ma Y, Liu Z, Cai J, et al. Electromagnetic interference shielding of graphene/epoxy composites. Carbon. 2009;47:922-5.

22. Cui Y, Kundalwal SI, Kumar S. Gas barrier performance of graphene/polymer nanocomposites. Carbon. 2016;98:313-33.

23. Sadeghinezhad E, Mehrali M, Saidur R, Mehrali M, Tahan Latibari S, Akhiani AR, et al. A comprehensive review on graphene nanofluids: recent research, development and applications. Energy Convers Manag. 2016;111:466-87.

24. Mattevi C, Kim H, Chhowalla M. A review of chemical vapour deposition of graphene on copper. J Mater Chem. 2011;21:3324-34.

25. Sun J, Nam Y, Lindvall N, Cole MT, Teo KBK, Woo Park Y, et al. Growth mechanism of graphene on platinum: Surface catalysis and carbon segregation. Appl Phys Lett. 2014;104:152107.

26. Wintterlin J, Bocquet M. Surface science graphene on metal surfaces. Surf Sci. 2009;603:1841-52.

27. Batzill M. The surface science of graphene: metal interfaces, CVD synthesis, nanoribbons, chemical modifications, and defects. Surf Sci Rep. 2012;67:83-115.

28. Novoselov KS, Geim AK, Morozov SV, Jiang D, Zhang Y, Dubonos SV, et al. Electric field effect in atomically thin carbon films. Science. 2004;306:666-9.

29. Edwards RS, Coleman KS. Graphene synthesis: relationship to applications. Nanoscale. 2013;5:38-51.

30. Hiura H, Ebbesen TW, Fujita J, Tanigaki K, Takada T. Role of $\mathrm{sp}^{3}$ defect structures in graphite and carbon nanotubes. Nature. 1994;367:148-51.

31. Ebbesen TW, Hiura H. Graphene in 3-dimensions: towards graphite origami. Adv Mater. 1995;7:582-6.

32. Bernhardt T, Kaiser B, Rademann K. Formation of superperiodic patterns on highly oriented pyrolytic graphite by manipulation of nanosized graphite sheets with the STM tip. Surf Sci. 1998;408:86-94.

33. Lu X, Yu M, Huang H, Ruoff RS. Tailoring graphite with the goal of achieving single sheets. Nanotechnology. 1999;10:269-72.

34. Roy H-V, Kallinger C, Marsen B, Sattler K. Manipulation of graphitic sheets using a tunneling microscope. J Appl Phys. 1998;83:4695-9.

35. Ci L, Song L, Jariwala D, ElÃ-as AL, Gao W, Terrones M, et al. Graphene shape control by multistage cutting and transfer. Adv Mater. 2009;21:4487-91.

36. Liang X, Chang ASP, Zhang Y, Harteneck BD, Choo H, Olynick DL, et al. Electrostatic force assisted exfoliation of prepatterned few-layer graphenes into device sites. Nano Lett. 2009;9:467-72.

37. Yi M, Shen Z. A review on mechanical exfoliation for scalable production of graphene. J Mater Chem. 2013;00:1-3.

38. Sharma S, Mathur RB, Dhakate S, Borah M, Dahiya M, Dhakate SR. Few layer graphene derived from wet ball milling of expanded graphite and few layer graphene based polymer composite. Mater Focus. 2014;3:300-9.

39. León V, Quintana M, Herrero MA, Fierro JLG, de la Hoz A, Prato M, et al. Few-layer graphenes from ball-milling of graphite with melamine. Chem Commun. 2011;47:10936.

40. Lin T, Tang Y, Wang Y, Bi H, Liu Z, Huang F, et al. Scotch-tapelike exfoliation of graphite assisted with elemental sulfur and graphene-sulfur composites for high-performance lithium-sulfur batteries. Energy Environ Sci. 2013;6:1283.

41. Del Rio-Castillo AE, Merino C, Díez-Barra E, Vázquez E. Selective suspension of single layer graphene mechanochemically exfoliated from carbon nanofibres. Nano Res. 2014;7:963-72. 
42. Hernandez Y, Nicolosi V, Lotya M, Blighe FM, Sun Z, De S, et al. High-yield production of graphene by liquid-phase exfoliation of graphite. Nat Nanotechnol. 2008;3:563-8.

43. Jayasena B, Subbiah S. A novel mechanical cleavage method for synthesizing few-layer graphenes. Nanoscale Res Lett. 2011;6:95.

44. Parvez K, Li R, Puniredd SR, Hernandez Y, Hinkel F, Wang S, et al. Electrochemically exfoliated graphene as solution-processable, highly conductive electrodes for organic electronics. ACS Nano. 2013;7:3598-606.

45. Lu J, Yang J, Wang J, Lim A, Wang S, Loh KP. One-pot synthesis of fluorescent carbon nanoribbons, nanoparticles, and graphene by the exfoliation of graphite in ionic liquids. ACS Nano. 2009;3:2367-75.

46. Mittal G, Dhand V, Rhee KY, Park S-J, Lee WR. A review on carbon nanotubes and graphene as fillers in reinforced polymer nanocomposites. J Ind Eng Chem. 2015;21:11-25.

47. Choucair M, Thordarson P, Stride JA. Gram-scale production of graphene based on solvothermal synthesis and sonication. Nat Nanotechnol. 2009;4:30-3.

48. Biswal M, Banerjee A, Deo M, Ogale S. From dead leaves to high energy density supercapacitors. Energy Environ Sci. 2013;6:1249.

49. Zhan D, Sun L, Ni ZH, Liu L, Fan XF, Wang Y, et al. $\mathrm{FeCl}_{3}$-based few-layer graphene intercalation compounds: single linear dispersion electronic band structure and strong charge transfer doping. Adv Funct Mater. 2010;20:3504-9.

50. Lee H, Kang J, Cho MS, Choi J-B, Lee Y. $\mathrm{MnO}_{2}$ /graphene composite electrodes for supercapacitors: the effect of graphene intercalation on capacitance. J Mater Chem. 2011;21:18215.

51. Verdejo R, Bernal MM, Romasanta LJ, Lopez-Manchado MA. Graphene filled polymer nanocomposites. J Mater Chem. 2011;21:3301-10.

52. Eswaraiah V, Jyothirmayee Aravind SS, Ramaprabhu S. Top down method for synthesis of highly conducting graphene by exfoliation of graphite oxide using focused solar radiation. $\mathbf{J}$ Mater Chem. 2011;21:6800.

53. Dato A. Graphene synthesized in atmospheric plasmas-a review. J Mater Res. 2019;34:214-30.

54. Askari S, Lotfi R, Seifkordi A, Rashidi AM, Koolivand H. A novel approach for energy and water conservation in wet cooling towers by using MWNTs and nanoporous graphene nanofluids. Energy Convers Manag. 2016;109:10-8.

55. Naghash A, Sattari S, Rashidi A. Experimental assessment of convective heat transfer coefficient enhancement of nanofluids prepared from high surface area nanoporous graphene. Int Commun Heat Mass Transf. 2016;78:127-34.

56. Ramón-Raygoza ED, Rivera-Solorio CI, Giménez-Torres E, Maldonado-Cortés D, Cardenas-Alemán E, Cué-Sampedro R. Development of nanolubricant based on impregnated multilayer graphene for automotive applications: Analysis of tribological properties. Powder Technol. 2016;302:363-71.

57. De Silva KKH, Huang HH, Joshi RK, Yoshimura M. Chemical reduction of graphene oxide using green reductants. Carbon. 2017;119:190-9.

58. Li Y, Li XM. Facile treatment of wastewater produced in Hummer's method to prepare $\mathrm{Mn}_{3} \mathrm{O}_{4}$ nanoparticles and study their electrochemical performance in an asymmetric supercapacitor. RSC Adv. 2013;3:2398-403.

59. Brodie BC. On the atomic weight of graphite. Philos Trans R Soc Lond. 1859;149:249-59.

60. Poh HL, San F. Nanoscale graphenes prepared by Staudenmaier, Hofmann and Hummers methods with consequent thermal exfoliation exhibit very different electrochemical. Nanoscale. 2012;4:3515-22.
61. Hofmann U, Holst R. Über die Säurenatur und die Methylierung von Graphitoxyd. Berichte der Dtsch Chem Gesellschaft (A B Ser). 1939;72:754-71.

62. Hofmann U, König E. Untersuchungen über Graphitoxyd. Zeitschrift für Anorg und Allg Chem. 1937;234:311-36.

63. Hummers WS, Offeman RE. Preparation of graphitic oxide. J Am Chem Soc. 1958;80:1339.

64. Shende RC, Ramaprabhu S. Application of few-layered reduced graphene oxide nanofluid as a working fluid for direct absorption solar collectors. J Nanosci Nanotechnol. 2017;17:1233-9.

65. Akhavan-Zanjani H, Saffar-Avval M, Mansourkiaei M, Sharif F, Ahadi M. Experimental investigation of laminar forced convective heat transfer of graphene-water nanofluid inside a circular tube. Int J Therm Sci. 2016;100:316-23.

66. Askari S, Lotfi R, Rashidi AM, Koolivand H, Koolivand-Salooki M. Rheological and thermophysical properties of ultra-stable kerosene-based $\mathrm{Fe}_{3} \mathrm{O}_{4} /$ graphene nanofluids for energy conservation. Energy Convers Manag. 2016;128:134-44.

67. Mehrali M, Sadeghinezhad E, Akhiani AR, Tahan Latibari S, Talebian S, Dolatshahi-Pirouz A, et al. An ecofriendly graphenebased nanofluid for heat transfer applications. J Clean Prod. 2016;137:555-66.

68. Zhang C, Zhang L, Xu H, Wang D, Ye B. Investigation of flow boiling performance and the resulting surface deposition of graphene oxide nanofluid in microchannels. Exp Therm Fluid Sci. 2017;86:1-10.

69. Esfahani MR, Languri EM. Exergy analysis of a shell-and-tube heat exchanger using graphene oxide nanofluids. Exp Therm Fluid Sci. 2017;83:100-6.

70. Marcano DC, Kosynkin DV, Berlin JM, Sinitskii A, Sun Z, Slesarev A, et al. Improved synthesis of graphene oxide. ACS Nano. 2010;4:4806-14.

71. Chin WL, Hashim U, Liu WW, Noriman NZ, Hidayah NMS. Effect on variation of $\mathrm{KMnO}_{4}$ amount for production of graphene oxide (GO). Adv Mater Res. 2015;1133:476-80.

72. Shen J, Hu Y, Shi M, Lu X, Qin C, Li C, et al. Fast and facile preparation of graphene oxide and reduced graphene oxide nanoplatelets. Chem Mater. 2009;21:3514-20.

73. Dreyer DR, Park S, Bielawski CW, Ruoff RS. The chemistry of graphene oxide. Chem Soc Rev. 2010;39:228-40.

74. Esmaeili-Faraj SH, Nasr Esfahany M. Absorption of hydrogen sulfide and carbon dioxide in water based nanofluids. Ind Eng Chem Res. 2016;55:4682-90.

75. Anin Vincely D, Natarajan E. Experimental investigation of the solar FPC performance using graphene oxide nanofluid under forced circulation. Energy Convers Manag. 2016;117:1-11.

76. Luo D, Wang F, Zhu J, Cao F, Liu Y, Li X, et al. Nanofluid of graphene-based amphiphilic Janus nanosheets for tertiary or enhanced oil recovery: high performance at low concentration. Proc Natl Acad Sci. 2016;113:7711-6.

77. Esfahani MR, Languri EM, Nunna MR. Effect of particle size and viscosity on thermal conductivity enhancement of graphene oxide nanofluid. Int Commun Heat Mass Transf. 2016;76:308-15.

78. Kim KM, Bang IC. Effects of graphene oxide nanofluids on heat pipe performance and capillary limits. Int J Therm Sci. 2016;100:346-56.

79. Mirzaei M, Azimi A. Heat transfer and pressure drop characteristics of graphene oxide/water nanofluid in a circular tube fitted with wire coil insert. Exp Heat Transf. 2016;29:173-87.

80. Mehrali M, Sadeghinezhad E, Rosen MA, Akhiani AR, Tahan Latibari S, Mehrali M, et al. Experimental investigation of thermophysical properties, entropy generation and convective heat transfer for a nitrogen-doped graphene nanofluid in a laminar flow regime. Adv Powder Technol. 2016;27:717-27. 
81. Báez DF, Pardo H, Laborda I, Marco JF, Yáñez C, Bollo S. Reduced graphene oxides: influence of the reduction method on the electrocatalytic effect towards nucleic acid oxidation. Nanomaterial. 2017;7:168.

82. Guex LG, Sacchi B, Peuvot KF, Andersson RL, Pourrahimi AM, Ström V, et al. Experimental review: chemical reduction of graphene oxide (GO) to reduced graphene oxide (rGO) by aqueous chemistry. Nanoscale. 2017;9:9562-71.

83. Gao W, Alemany LB, Ci L, Ajayan PM. New insights into the structure and reduction of graphite oxide. Nat Chem. 2009;1:403-8.

84. Larciprete R, Fabris S, Sun T, Lacovig P, Baraldi A, Lizzit S. Dual path mechanism in the thermal reduction of graphene oxide. J Am Chem Soc. 2011;133:17315-21.

85. Hun S. Thermal reduction of graphene oxide. Phys Appl Graphene Exp. 2011. https://doi.org/10.5772/14156

86. Chee SY, Poh HL, Chua CK, Saněk F, Sofer Z, Pumera M. Influence of parent graphite particle size on the electrochemistry of thermally reduced graphene oxide. Phys Chem Chem Phys. 2012;14:12794-9.

87. Ping J, Wang Y, Fan K, Wu J, Ying Y. Direct electrochemical reduction of graphene oxide on ionic liquid doped screenprinted electrode and its electrochemical biosensing application. Biosens Bioelectron. 2011;28:204-9.

88. Liu C, Wang K, Luo S, Tang Y, Chen L. Direct electrodeposition of graphene enabling the one-step synthesis of graphenemetal nanocomposite films. Small. 2011;7:1203-6.

89. Jiang Y, Lu Y, Li F, Wu T, Niu L, Chen W. Facile electrochemical codeposition of "clean" graphene-Pd nanocomposite as an anode catalyst for formic acid electrooxidation. Electrochem Commun. 2012;19:21-4.

90. Chang H-H, Chang C-K, Tsai Y-C, Liao C-S. Electrochemically synthesized graphene/polypyrrole composites and their use in supercapacitor. Carbon. 2012;50:2331-6.

91. Toh SY, Loh KS, Kamarudin SK, Daud WRW. Graphene production via electrochemical reduction of graphene oxide: synthesis and characterisation. Chem Eng J. 2014;251:422-34.

92. Park SD, Won Lee S, Kang S, Bang IC, Kim JH, Shin HS, et al. Effects of nanofluids containing graphene/grapheneoxide nanosheets on critical heat flux. Appl Phys Lett. 2010;97:023103.

93. Yu W, Xie H, Chen L, Li Y, Li D. The preparation and thermal conductivities enhacement of nanofluids containing graphene oxide nanosheets. In: 2010 14th international heat transfer conference, vol 6. ASME; 2010. p. 569-73.

94. Yu W, Xie H, Bao D. Enhanced thermal conductivities of nanofluids containing graphene oxide nanosheets. Nanotechnology. 2010;21:055705.

95. Yu W, Xie H, Chen W. Experimental investigation on thermal conductivity of nanofluids containing graphene oxide nanosheets. J Appl Phys. 2010;107:094317.

96. Baby TT, Ramaprabhu S. Investigation of thermal and electrical conductivity of graphene based nanofluids. J Appl Phys. 2010;108:124308.

97. Baby TT, Sundara R. Synthesis and transport properties of metal oxide decorated graphene dispersed nanofluids. J Phys Chem C. 2011;115:8527-33.

98. Baby TT, Ramaprabhu S. Enhanced convective heat transfer using graphene dispersed nanofluids. Nanoscale Res Lett. 2011;6:289.

99. Baby TT, Ramaprabhu S. Synthesis and nanofluid application of silver nanoparticles decorated graphene. J Mater Chem. 2011;21:9702.

100. Jyothirmayee Aravind SS, Ramaprabhu S. Surfactant free graphene nanosheets based nanofluids by in situ reduction of alkaline graphite oxide suspensions. J Appl Phys. 2011;110:124326.
101. Park SD, Lee SW, Kang S, Kim SM, Bang IC. Pool boiling CHF enhancement by graphene-oxide nanofluid under nuclear coolant chemical environments. Nucl Eng Des. 2012;252:184-91.

102. Park SD, Bang IC. Flow boiling CHF enhancement in an external reactor vessel cooling (ERVC) channel using graphene oxide nanofluid. Nucl Eng Des. 2013;265:310-8.

103. Dhar P, Sen Gupta S, Chakraborty S, Pattamatta A, Das SK. The role of percolation and sheet dynamics during heat conduction in poly-dispersed graphene nanofluids. Appl Phys Lett. 2013;102:163114.

104. Ghozatloo A, Shariaty-Niasar M, Rashidi AM. Preparation of nanofluids from functionalized graphene by new alkaline method and study on the thermal conductivity and stability. Int Commun Heat Mass Transf. 2013;42:89-94.

105. Kole M, Dey TK. Investigation of thermal conductivity, viscosity, and electrical conductivity of graphene based nanofluids. J Appl Phys. 2013;113:084307.

106. Theres Baby T, Sundara R. Synthesis of silver nanoparticle decorated multiwalled carbon nanotubes-graphene mixture and its heat transfer studies in nanofluid. AIP Adv. 2013;3:012111.

107. Akhavan-Zanjani H, Saffar-Avval M, Mansourkiaei M, Ahadi M, Sharif F. Turbulent convective heat transfer and pressure drop of graphene-water nanofluid flowing inside a horizontal circular tube. J Dispers Sci Technol. 2014;35:1230-40.

108. Zhang L, Yu Z, Li D, Fan L, Zhu Y, Hong R, et al. Enhanced critical heat flux during quenching of extremely dilute aqueous colloidal suspensions with graphene oxide nanosheets. J Heat Transfer. 2013;135:054502.

109. Liu J, Wang F, Zhang L, Fang X, Zhang Z. Thermodynamic properties and thermal stability of ionic liquid-based nanofluids containing graphene as advanced heat transfer fluids for medium-to-high-temperature applications. Renew Energy. 2014;63:519-23.

110. Park SD, Bang IC. Experimental study of a universal CHF enhancement mechanism in nanofluids using hydrodynamic instability. Int J Heat Mass Transf. 2014;70:844-50.

111. Liu K, Chen S, Luo Y, Jia D, Gao H, Hu G, et al. Noncovalently functionalized pristine graphene/metal nanoparticle hybrid for conductive composites. Compos Sci Technol. 2014;94:1-7.

112. Park SS, Kim NJ. Influence of the oxidation treatment and the average particle diameter of graphene for thermal conductivity enhancement. J Ind Eng Chem. 2014;20:1911-5.

113. Li P, Zheng Y, Wu Y, Qu P, Yang R, Zhang A. Nanoscale ionic graphene material with liquid-like behavior in the absence of solvent. Appl Surf Sci. 2014;314:983-90.

114. Mehrali M, Sadeghinezhad E, Tahan Latibari S, Mehrali M, Togun H, Zubir MNM, et al. Preparation, characterization, viscosity, and thermal conductivity of nitrogen-doped graphene aqueous nanofluids. J Mater Sci. 2014;49:7156-71.

115. Hajjar Z, Rashidi AM, Ghozatloo A. Enhanced thermal conductivities of graphene oxide nanofluids. Int Commun Heat Mass Transf. 2014;57:128-31.

116. Esmaeili Faraj SH, Nasr Esfahany M, Jafari-Asl M, Etesami N. Hydrogen sulfide bubble absorption enhancement in water-based nanofluids. Ind Eng Chem Res. 2014;53:16851-8.

117. Li X, Chen Y, Mo S, Jia L, Shao X. Effect of surface modification on the stability and thermal conductivity of waterbased $\mathrm{SiO}_{2}$-coated graphene nanofluid. Thermochim Acta. 2014;595:6-10.

118. Hadadian M, Goharshadi EK, Youssefi A. Electrical conductivity, thermal conductivity, and rheological properties of graphene oxide-based nanofluids. J Nanoparticle Res. 2014;16:2788.

119. Zubir MNM, Badarudin A, Kazi SN, Huang NM, Misran M, Sadeghinezhad E, et al. Experimental investigation on the use of reduced graphene oxide and its hybrid complexes in improving 
closed conduit turbulent forced convective heat transfer. Exp Therm Fluid Sci. 2015;66:290-303.

120. Liu J, Ye Z, Zhang L, Fang X, Zhang Z. A combined numerical and experimental study on graphene/ionic liquid nanofluid based direct absorption solar collector. Sol Energy Mater Sol Cells. 2015;136:177-86.

121. Kazi SN, Badarudin A, Zubir MNM, Ming HN, Misran M, Sadeghinezhad $\mathrm{E}$, et al. Investigation on the use of graphene oxide as novel surfactant to stabilize weakly charged graphene nanoplatelets. Nanoscale Res Lett. 2015;10:212.

122. Mohd Zubir MN, Badarudin A, Kazi SN, Huang NM, Misran M, Sadeghinezhad E, et al. Highly dispersed reduced graphene oxide and its hybrid complexes as effective additives for improving thermophysical property of heat transfer fluid. Int J Heat Mass Transf. 2015;87:284-94.

123. Asirvatham LG, Wongwises S, Babu J. Heat transfer performance of a glass thermosyphon using graphene-acetone nanofluid. J Heat Transfer. 2015;137:111502.

124. Mahmudul Haque AKM, Kwon S, Kim J, Noh J, Huh S, Chung $\mathrm{H}$, et al. An experimental study on thermal characteristics of nanofluid with graphene and multi-wall carbon nanotubes. J Cent South Univ. 2015;22:3202-10.

125. Li Tong W, Ong W-J, Chai S-P, Tan MK, Mun Hung Y. Enhanced evaporation strength through fast water permeation in grapheneoxide deposition. Sci Rep. 2015;5:11896.

126. Fan L-W, Li J-Q, Li D-Y, Zhang L, Yu Z-T, Cen K-F. The effect of concentration on transient pool boiling heat transfer of graphenebased aqueous nanofluids. Int J Therm Sci. 2015;91:83-95.

127. Park S-S, Kim YH, Jeon YH, Hyun MT, Kim N-J. Effects of spray-deposited oxidized multi-wall carbon nanotubes and graphene on pool-boiling critical heat flux enhancement. J Ind Eng Chem. 2015;24:276-83.

128. Ghozatloo A, Rashidi A, Shariaty-Niassar M. Convective heat transfer enhancement of graphene nanofluids in shell and tube heat exchanger. Exp Therm Fluid Sci. 2014;53:136-41.

129. Ma W, Yang F, Shi J, Wang F, Zhang Z, Wang S. Silicone based nanofluids containing functionalized graphene nanosheets. Colloids Surf A Physicochem Eng Asp. 2013;431:120-6.

130. Shende R, Sundara R. Nitrogen doped hybrid carbon based composite dispersed nanofluids as working fluid for low-temperature direct absorption solar collectors. Sol Energy Mater Sol Cells. 2015;140:9-16.

131. Jia L, Chen Y, Lei S, Mo S, Luo X, Shao X. External electromagnetic field-aided freezing of CMC-modified graphene/water nanofluid. Appl Energy. 2016;162:1670-7.

132. Agarwal DK, Vaidyanathan A, Sunil Kumar S. Experimental investigation on thermal performance of kerosene-graphene nanofluid. Exp Therm Fluid Sci. 2016;71:126-37.

133. Tharayil T, Asirvatham LG, Ravindran V, Wongwises S. Thermal performance of miniature loop heat pipe with graphene-water nanofluid. Int J Heat Mass Transf. 2016;93:957-68.

134. Ahammed N, Asirvatham LG, Wongwises S. Effect of volume concentration and temperature on viscosity and surface tension of graphene-water nanofluid for heat transfer applications. J Therm Anal Calorim. 2016;123:1399-409.

135. Sarsam WS, Amiri A, Kazi SN, Badarudin A. Stability and thermophysical properties of non-covalently functionalized graphene nanoplatelets nanofluids. Energy Convers Manag. 2016;116:101-11.

136. Vakili M, Hosseinalipour SM, Delfani S, Khosrojerdi S, Karami M. Experimental investigation of graphene nanoplatelets nanofluid-based volumetric solar collector for domestic hot water systems. Sol Energy. 2016;131:119-30.

137. Agromayor R, Cabaleiro D, Pardinas AA, Vallejo JP, FernandezSeara J, Lugo L. Heat transfer performance of functionalized graphene nanoplatelet aqueous nanofluids. Materials. 2016;9:455.
138. Sathishkumar A, Kumaresan V, Velraj R. Solidification characteristics of water based graphene nanofluid PCM in a spherical capsule for cool thermal energy storage applications. Int J Refrig. 2016;66:73-83.

139. Mehrali M, Sadeghinezhad E, Azizian R, Akhiani AR, Tahan Latibari S, Mehrali M, et al. Effect of nitrogen-doped graphene nanofluid on the thermal performance of the grooved copper heat pipe. Energy Convers Manag. 2016;118:459-73.

140. Lee W, Kihm KD, Park JS, Lee W, Kim H, Lee C, et al. Wetting of nanofluids with nanoparticles of opposite surface potentials on pristine CVD graphene. Exp Fluids. 2016;57:1-10.

141. Sarsam WS, Amiri A, Zubir MNM, Yarmand H, Kazi SN, Badarudin A. Stability and thermophysical properties of waterbased nanofluids containing triethanolamine-treated graphene nanoplatelets with different specific surface areas. Colloids Surf A Physicochem Eng Asp. 2016;500:17-31.

142. Vakili M, Hosseinalipour SM, Delfani S, Khosrojerdi S. Photothermal properties of graphene nanoplatelets nanofluid for lowtemperature direct absorption solar collectors. Sol Energy Mater Sol Cells. 2016;152:187-91.

143. Tahani M, Vakili M, Khosrojerdi S. Experimental evaluation and ANN modeling of thermal conductivity of graphene oxide nanoplatelets/deionized water nanofluid. Int Commun Heat Mass Transf. 2016;76:358-65.

144. Myekhlai M, Lee T, Baatar B, Chung H, Jeong H. Thermal conductivity on the nanofluid of graphene and silver nanoparticles composite material. J Nanosci Nanotechnol. 2016;16:1633-7.

145. Yarmand H, Gharehkhani S, Shirazi SFS, Amiri A, Montazer E, Arzani HK, et al. Nanofluid based on activated hybrid of biomass carbon/graphene oxide: Synthesis, thermo-physical and electrical properties. Int Commun Heat Mass Transf. 2016;72:10-5.

146. Solangi KH, Amiri A, Luhur MR, Ghavimi SAA, Zubir MNM, Kazi SN, et al. Experimental investigation of the propylene glycol-treated graphene nanoplatelets for the enhancement of closed conduit turbulent convective heat transfer. Int Commun Heat Mass Transf. 2016;73:43-53.

147. Yarmand H, Gharehkhani S, Shirazi SFS, Amiri A, Alehashem MS, Dahari M, et al. Experimental investigation of thermophysical properties, convective heat transfer and pressure drop of functionalized graphene nanoplatelets aqueous nanofluid in a square heated pipe. Energy Convers Manag. 2016;114:38-49.

148. Haque A, Kim T, Oh GS, Kim J. Synthesis of graphene/multiwalled carbon nanotube composite and its nanofluid preparation. Nanosci Nanotechnol Lett. 2016;8:316-23.

149. $\mathrm{Hu} \mathrm{Y,} \mathrm{Li} \mathrm{H,} \mathrm{He} \mathrm{Y,} \mathrm{Wang} \mathrm{L.} \mathrm{Role} \mathrm{of} \mathrm{nanoparticles} \mathrm{on} \mathrm{boiling}$ heat transfer performance of ethylene glycol aqueous solution based graphene nanosheets nanofluid. Int J Heat Mass Transf. 2016;96:565-72.

150. Khosrojerdi S, Vakili M, Yahyaei M, Kalhor K. Thermal conductivity modeling of graphene nanoplatelets/deionized water nanofluid by MLP neural network and theoretical modeling using experimental results. Int Commun Heat Mass Transf. 2016;74:11-7.

151. Sadeghinezhad E, Mehrali M, Rosen MA, Akhiani AR, Tahan Latibari S, Mehrali M, et al. Experimental investigation of the effect of graphene nanofluids on heat pipe thermal performance. Appl Therm Eng. 2016;100:775-87.

152. Iranmanesh S, Mehrali M, Sadeghinezhad E, Ang BC, Ong HC, Esmaeilzadeh A. Evaluation of viscosity and thermal conductivity of graphene nanoplatelets nanofluids through a combined experimental-statistical approach using respond surface methodology method. Int Commun Heat Mass Transf. 2016;79:74-80.

153. Selvam C, Balaji T, Mohan Lal D, Harish S. Convective heat transfer coefficient and pressure drop of water-ethylene glycol mixture with graphene nanoplatelets. Exp Therm Fluid Sci. 2017;80:67-76. 
154. Abo-Zahhad EM, El-Shazly AH, El-Kady MF. Experimental study of pressure drops across microtube using graphene and magnetic graphene nanofluid. AIP Conf Proc. 2017;020015:020015.

155. Abd Elhafez SE, Abo-Zahhad EM, El-Shazly AH, Elkady MF. Experimental investigate of heat transfer for graphene/ water nanofluid in micro heat exchanger. AIP Conf Proc. 2017;1814:020014.

156. Wang N, Xu G, Li S, Zhang X. Thermal properties and solar collection characteristics of oil-based nanofluids with low graphene concentration. Energy Procedia. 2017;105:194-9.

157. Qing SH, Rashmi W, Khalid M, Gupta TCSM, Nabipoor M, Hajibeigy MT. Thermal conductivity and electrical properties of hybrid $\mathrm{SiO}_{2}$-graphene naphthenic mineral oil nanofluid as potential transformer oil. Mater Res Express. 2017;4:015504.

158. Cabaleiro D, Colla L, Barison S, Lugo L, Fedele L, Bobbo S. Heat transfer capability of (ethylene glycol + water)-based nanofluids containing graphene nanoplatelets: design and thermophysical profile. Nanoscale Res Lett. 2017;12:1.

159. Mehrali M, Sadeghinezhad E, Akhiani AR, Tahan Latibari S, Metselaar HSC, Kherbeet AS, et al. Heat transfer and entropy generation analysis of hybrid graphene $/ \mathrm{Fe}_{3} \mathrm{O}_{4}$ ferro-nanofluid flow under the influence of a magnetic field. Powder Technol. 2017;308:149-57.

160. Su X, Zhang M, Han W, Guo X. Experimental study on the heat transfer performance of an oscillating heat pipe with self-rewetting nanofluid. Int J Heat Mass Transf. 2016;100:378-85.

161. Yarmand H, Gharehkhani S, Shirazi SFS, Goodarzi M, Amiri A, Sarsam WS, et al. Study of synthesis, stability and thermophysical properties of graphene nanoplatelet/platinum hybrid nanofluid. Int Commun Heat Mass Transf. 2016;77:15-21.

162. Selvam C, Lal DM, Harish S. Thermal conductivity enhancement of ethylene glycol and water with graphene nanoplatelets. Thermochim Acta. 2016;642:32-8.

163. Ho CY, Yusup S, Soon CV, Arpin MT. Rheological behaviour of graphene nano-sheets in hydrogenated oil-based drilling fluid. Procedia Eng. 2016;148:49-56.

164. Kumar V, Tiwari AK, Ghosh SK. Effect of variable spacing on performance of plate heat exchanger using nanofluids. Energy. 2016;114:1107-19.

165. Zhang L, Chen L, Liu J, Fang X, Zhang Z. Effect of morphology of carbon nanomaterials on thermo-physical characteristics, optical properties and photo-thermal conversion performance of nanofluids. Renew Energy. 2016;99:888-97.

166. Ahammed N, Asirvatham LG, Wongwises S. Entropy generation analysis of graphene-alumina hybrid nanofluid in multiport minichannel heat exchanger coupled with thermoelectric cooler. Int J Heat Mass Trans. 2016;103:1084-97.

167. Singh RK, Sharma AK, Dixit AR, Tiwari AK, Pramanik A, Mandal A. Performance evaluation of alumina-graphene hybrid nanocutting fluid in hard turning. J Clean Prod. 2017;162:830-45.

168. Kim S, Tserengombo B, Choi SH, Noh J, Huh S, Choi B, et al. Experimental investigation of dispersion characteristics and thermal conductivity of various surfactants on carbon based nanomaterial. Int Commun Heat Mass Transf. 2018;91:95-102.

169. Yudong L, Yongkun G, Jiangqing W, Shichao G, Chuangjian S, Quangui P. Nucleation mechanism of nanofluid drops under acoustic levitation. Appl Therm Eng. 2018;130:40-8.

170. Imani-Mofrad P, Zeinali Heris S, Shanbedi M. Experimental investigation of the effect of different nanofluids on the thermal performance of a wet cooling tower using a new method for equalization of ambient conditions. Energy Convers Manag. 2018;158:23-35.

171. Iranmanesh S, Ong HC, Ang BC, Sadeghinezhad E, Esmaeilzadeh A, Mehrali M. Thermal performance enhancement of an evacuated tube solar collector using graphene nanoplatelets nanofluid. J Clean Prod. 2017;162:121-9.

172. Sumanth S, Babu Rao P, Krishna V, Seetharam TR, Seetharamu $\mathrm{KN}$. Effect of carboxyl graphene nanofluid on automobile radiator performance. Heat Transf Asian Res. 2018;47:669-83.

173. Verma SK, Tiwari AK, Chauhan DS. Experimental evaluation of flat plate solar collector using nanofluids. Energy Convers Manag. 2017;134:103-15.

174. Sadeghinezhad E, Mehrali M, Akhiani AR, Tahan Latibari S, Dolatshahi-Pirouz A, Metselaar HSC, et al. Experimental study on heat transfer augmentation of graphene based ferrofluids in presence of magnetic field. Appl Therm Eng. 2017;114:415-27.

175. Chen L, Liu J, Fang X, Zhang Z. Reduced graphene oxide dispersed nanofluids with improved photo-thermal conversion performance for direct absorption solar collectors. Sol Energy Mater Sol Cells. 2017;163:125-33.

176. Sadri R, Hosseini M, Kazi SN, Bagheri S, Zubir N, Ahmadi $\mathrm{G}$, et al. A novel, eco-friendly technique for covalent functionalization of graphene nanoplatelets and the potential of their nanofluids for heat transfer applications. Chem Phys Lett. 2017;675:92-7.

177. Syam Sundar L, Singh MK, Ferro MC, Sousa ACM. Experimental investigation of the thermal transport properties of graphene oxide $/ \mathrm{Co}_{3} \mathrm{O}_{4}$ hybrid nanofluids. Int Commun Heat Mass Transf. 2017;84:1-10.

178. Wang X, Hu Y, Li T, He Y. Experimental investigation of graphene nanofluid and numerical simulation of its natural convection in a square enclosure. Nanosci Nanotechnol Lett. 2017;9:640-9.

179. Selvam C, Mohan Lal D, Harish S. Thermal conductivity and specific heat capacity of water-ethylene glycol mixture-based nanofluids with graphene nanoplatelets. J Therm Anal Calorim. 2017;129:947-55.

180. Selvam C, Mohan Lal D, Harish S. Enhanced heat transfer performance of an automobile radiator with graphene based suspensions. Appl Therm Eng. 2017;123:50-60.

181. Chai YH, Yusup S, Chok VS, Irawan S, Singh JSDB. Thermophysical properties of graphene nanosheets-hydrogenated oil based nanofluid for drilling fluid improvements. Appl Therm Eng. 2017;122:794-805.

182. Zhou Y, Cui X, Weng J, Shi S, Han H, Chen C. Experimental investigation of the heat transfer performance of an oscillating heat pipe with graphene nanofluids. Powder Technol. 2018;332:371-80.

183. Liu X, Wang X, Huang J, Cheng G, He Y. Volumetric solar steam generation enhanced by reduced graphene oxide nanofluid. Appl Energy. 2018;220:302-12.

184. Ranjbarzadeh R, Karimipour A, Afrand M, Isfahani AHM, Shirneshan A. Empirical analysis of heat transfer and friction factor of water/graphene oxide nanofluid flow in turbulent regime through an isothermal pipe. Appl Therm Eng. 2017;126:538-47.

185. Hussien AA, Abdullah MZ, Yusop NM, Al-Nimr MA, Atieh MA, Mehrali M. Experiment on forced convective heat transfer enhancement using MWCNTs/GNPs hybrid nanofluid and minitube. Int J Heat Mass Transf. 2017;115:1121-31.

186. Selvam C, Solaimalai Raja R, Mohan Lal D, Harish S. Overall heat transfer coefficient improvement of an automobile radiator with graphene based suspensions. Int J Heat Mass Transf. 2017:115:580-8.

187. Vakilinejad A, Aroon MA, Al-Abri M, Bahmanyar H, Myint MTZ, Vakili-Nezhaad GR. Experimental and theoretical investigation of thermal conductivity of some water-based nanofluids. Chem Eng Commun. 2018;205:610-23.

188. Vallejo JP, Gómez-Barreiro S, Cabaleiro D, Gracia-Fernández C, Fernández-Seara J, Lugo L. Flow behaviour of suspensions of 
functionalized graphene nanoplatelets in propylene glycol-water mixtures. Int Commun Heat Mass Transf. 2018;91:150-7.

189. Ranjbarzadeh R, Meghdadi Isfahani AH, Afrand M, Karimipour A, Hojaji M. An experimental study on heat transfer and pressure drop of water/graphene oxide nanofluid in a copper tube under air cross-flow: applicable as a heat exchanger. Appl Therm Eng. 2017;125:69-79.

190. Yu X, Wu Q, Zhang H, Zeng G, Li W, Qian Y, et al. Investigation on synthesis, stability, and thermal conductivity properties of water-based $\mathrm{SnO}_{2}$ /reduced graphene oxide nanofluids. Materials. 2017;11:1-13.

191. Nazari MA, Ghasempour R, Ahmadi MH, Heydarian G, Shafii MB. Experimental investigation of graphene oxide nanofluid on heat transfer enhancement of pulsating heat pipe. Int Commun Heat Mass Transf. 2018;91:90-4.

192. Lee D, Park J, Lee M, Lee G. Aging-resistant nano fluids containing covalent functionalized boron nitride nanosheets. Nanotechnology. 2017;28:405704.

193. Zhai P, Wang Y, Liu C, Wang X, Feng SP. Electric-field-tunable conductivity in graphene/water and graphene/ice systems. Small. 2017;13:1-8.

194. Luo D, Wang F, Zhu J, Tang L, Zhu Z, Bao J, et al. Secondary oil recovery using graphene-based amphiphilic Janus nanosheet fluid at an ultralow concentration. Ind Eng Chem Res. 2017;56:11125-32.

195. Osama M, Rashmi W, Kaveh S, Khalid M, Gupta T. Theoretical modelling of thermal conductivity of deep eutectic solvent based nanofluid. J Eng Sci Technol. 2017;12:809-19.

196. Tharayil T, Asirvatham LG, Dau MJ, Wongwises S. Entropy generation analysis of a miniature loop heat pipe with graphenewater nanofluid: thermodynamics model and experimental study. Int J Heat Mass Transf. 2017;106:407-21.

197. Vakili M, Khosrojerdi S, Aghajannezhad P, Yahyaei M. A hybrid artificial neural network-genetic algorithm modeling approach for viscosity estimation of graphene nanoplatelets nanofluid using experimental data. Int Commun Heat Mass Transf. 2017;82:40-8.

198. Wang Y, Al-Saaidi HAI, Kong M, Alvarado JL. Thermophysical performance of graphene based aqueous nanofluids. Int J Heat Mass Transf. 2018;119:408-17.

199. Ahammed N, Asirvatham LG, Titus J, Bose JR, Wongwises S. Measurement of thermal conductivity of graphene-water nanofluid at below and above ambient temperatures. Int Commun Heat Mass Transf. 2016;70:66-74.

200. Amiri A, Ahmadi G, Shanbedi M, Etemadi M, Mohd Zubir MN, Chew BT, et al. Heat transfer enhancement of water-based highly crumpled few-layer graphene nanofluids. RSC Adv. 2016;6:105508-27.

201. Yu W, Xie H, Bao D. Enhanced thermal conductivities of nanofluids containing graphene oxide nanosheets. Nanotechnology. 2009;21:055705.

202. Martin-Gallego M, Verdejo R, Khayet M, de Zarate J, Essalhi M, Lopez-Manchado M. Thermal conductivity of carbon nanotubes and graphene in epoxy nanofluids and nanocomposites. Nanoscale Res Lett. 2011;6:610.

203. Wang F, Wang F, Fan X, Lian Z. Experimental study on an inverter heat pump with HFC125 operating near the refrigerant critical point. Appl Therm Eng. 2012;39:1-7.

204. Park JS, Kihm KD, Kim H, Lim G, Cheon S, Lee JS. Wetting and evaporative aggregation of nanofluid droplets on CVD-synthesized hydrophobic graphene surfaces. Langmuir. 2014;30:8268-75.

205. Sun Z, Pöller S, Huang X, Guschin D, Taetz C, Ebbinghaus P, et al. High-yield exfoliation of graphite in acrylate polymers: a stable few-layer graphene nanofluid with enhanced thermal conductivity. Carbon. 2013;64:288-94.
206. Lee SW, Kim KM, Bang IC. Study on flow boiling critical heat flux enhancement of graphene oxide/water nanofluid. Int J Heat Mass Transf. 2013;65:348-56.

207. Haque AKMM, Kim S, Kim J, Noh J, Huh S, Choi B, et al. Surface modification of graphene nanoparticles by acid treatment and grinding process. J Nanosci Nanotechnol. 2018;18:645-50.

208. Vallejo JP, Pérez-Tavernier J, Cabaleiro D, Fernández-Seara J, Lugo L. Potential heat transfer enhancement of functionalized graphene nanoplatelet dispersions in a propylene glycolwater mixture. Thermophysical profile. J Chem Thermodyn. 2018;123:174-84.

209. Askari S, Koolivand H, Pourkhalil M, Lotfi R, Rashidi A. Investigation of $\mathrm{Fe}_{3} \mathrm{O}_{4} /$ graphene nanohybrid heat transfer properties: experimental approach. Int Commun Heat Mass Transf. 2017;87:30-9.

210. Zhou M, Xia G, Li J, Chai L, Zhou L. Analysis of factors influencing thermal conductivity and viscosity in different kinds of surfactant solutions. Exp Therm Fluid Sci. 2012;36:22-9.

211. Khosrojerdi S, Lavasani AM, Vakili M. Experimental study of photothermal specifications and stability of graphene oxide nanoplatelets nanofluid as working fluid for low-temperature Direct Absorption Solar Collectors (DASCs). Sol Energy Mater Sol Cells. 2017;164:32-9.

212. Ahmadi A, Ganji DD, Jafarkazemi F. Analysis of utilizing graphene nanoplatelets to enhance thermal performance of flat plate solar collectors. Energy Convers Manag. 2016;126:1-11.

213. Yarmand H, Gharehkhani S, Ahmadi G, Shirazi SFS, Baradaran S, Montazer E, et al. Graphene nanoplatelets-silver hybrid nanofluids for enhanced heat transfer. Energy Convers Manag. 2015;100:419-28.

214. Kulkarni P, Sureshkumar R, Biswas P. Multiscale simulation of irreversible deposition in presence of double layer interactions. J Colloid Interface Sci. 2003;260:36-48.

215. Tchalala MR, Anjum DH, Chaieb S. Effect of ionicl liquid (emim BF 4) on the dispersion of gold nanoparticles. J Phys Conf Ser. 2016;758:012020.

216. Heller W. Effects of macromolecular compounds in disperse systems. Pure Appl Chem. 1966;12:249-74.

217. Heller W, Pugh TL. "Steric protection" of hydrophobic colloidal particles by adsorption of flexible macromolecules. J Chem Phys. 1954;22:1778.

218. Turkevich J, Stevenson PC, Hillier J. A study of the nucleation and growth processes in the synthesis of colloidal gold. Discuss Faraday Soc. 1951;11:55.

219. Turkevich J. Colloidal gold. Part I. Gold Bull. 1985;18:86-91.

220. Yu W, Xie H. A review on nanofluids: preparation, stability mechanisms, and applications. J Nanomater. 2012;2012:1687-4110.

221. Bharti S. A critical review on flocculants and flocculation. Non-Metallic Mater Sci. 2019. https://doi.org/10.30564/omms. v1i1.645.

222. Wei $X$, Wang L. Particuology synthesis and thermal conductivity of microfluidic copper nanofluids. Particuology. 2010;8:262-71.

223. Li J, Cui J, Yang Z, Qiu H, Tang Z, Yang J. Stabilizing graphene layers by intercalating laponite between them. New Carbon Mater. 2018;33:19-25.

224. Mahanta NK, Abramson AR. Thermal conductivity of graphene and graphene oxide nanoplatelets. In: 13th Intersoc Conf Therm Thermomechanical Phenom Electron Syst. IEEE; 2012. p. 1-6.

225. Angayarkanni SA, Philip J. Review on thermal properties of nanofluids: recent developments. Adv Colloid Interface Sci. 2015;225:146-76.

226. Ali HM, Arshad W. Effect of channel angle of pin-fin heat sink on heat transfer performance using water based graphene nanoplatelets nanofluids. Int J Heat Mass Transf. 2017;106:465-72. 
227. Arshad W, Ali HM. Graphene nanoplatelets nanofluids thermal and hydrodynamic performance on integral fin heat sink. Int J Heat Mass Transf. 2017;107:995-1001.

228. Amiri A, Shanbedi M, Chew BT, Kazi SN, Solangi KH. Toward improved engine performance with crumpled nitrogen-doped graphene based water-ethylene glycol coolant. Chem Eng J. 2016;289:583-95.

229. Goodarzi M, Kherbeet AS, Afrand M, Sadeghinezhad E, Mehrali $\mathrm{M}$, Zahedi $\mathrm{P}$, et al. Investigation of heat transfer performance and friction factor of a counter-flow double-pipe heat exchanger using nitrogen-doped, graphene-based nanofluids. Int Commun Heat Mass Transf. 2016;76:16-23.

230. Zuber N, Novak. Hydrodynamic aspects of boiling heat transfer (Thesis). Oak Ridge, TN; 1959.

231. Zhang L, Fan L, Yu Z, Cen K. An experimental investigation of transient pool boiling of aqueous nanofluids with graphene oxide nanosheets as characterized by the quenching method. Int J Heat Mass Transf. 2014;73:410-4.

232. Rose BAJ, Singh H, Verma N, Tassou S, Suresh S, Anantharaman N, et al. Investigations into nanofluids as direct solar radiation collectors. Sol Energy. 2017;147:426-31.

233. Asadi A, Pourfattah F, Miklós Szilágyi I, Afrand M, Żyła G, Seon Ahn H, et al. Effect of sonication characteristics on stability, thermophysical properties, and heat transfer of nanofluids: A comprehensive review. Ultrason Sonochem. 2019;58:104701.

Publisher's Note Springer Nature remains neutral with regard to jurisdictional claims in published maps and institutional affiliations. 